BIS Working Papers

No 247

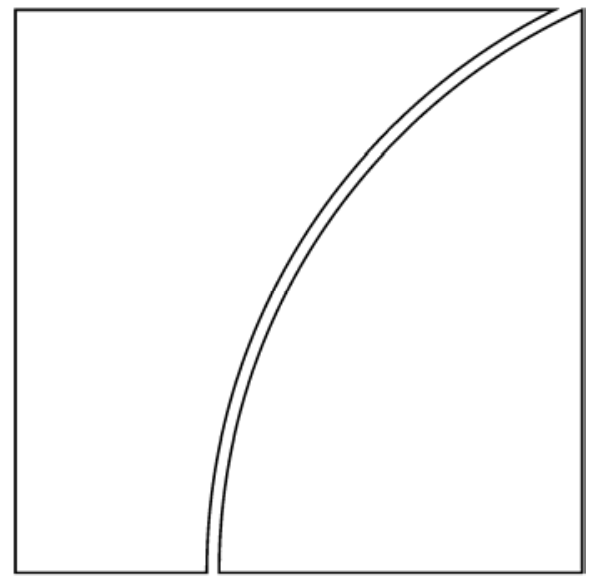

What drives the current account in commodity exporting countries? The cases of Chile and New Zealand

by Juan Pablo Medina, Anella Munro and Claudio Soto

Monetary and Economic Department

February 2008 
BIS Working Papers are written by members of the Monetary and Economic Department of the Bank for International Settlements, and from time to time by other economists, and are published by the Bank. The views expressed in them are those of their authors and not necessarily the views of the BIS.

Copies of publications are available from:

Bank for International Settlements

Press \& Communications

$\mathrm{CH}-4002$ Basel, Switzerland

E-mail: publications@bis.org

Fax: +41612809100 and +41612808100

This publication is available on the BIS website (www.bis.org).

(c) Bank for International Settlements 2008. All rights reserved. Limited extracts may be reproduced or translated provided the source is stated.

ISSN 1020-0959 (print)

ISSN 1682-7678 (online) 


\begin{abstract}
This paper uses an open economy DSGE model with a commodity sector and nominal and real rigidities to ask what factors account for current account developments in two small commodity exporting countries. We estimate the model, using Bayesian techniques, on Chilean and on New Zealand data, and investigate the structural factors that explain the behaviour of the two countries' current accounts. We find that foreign financial conditions, investment-specific shocks, and foreign demand account for the bulk of the variation of the current accounts of the two countries. In the case of New Zealand fluctuations in commodity export prices have also been important. Monetary and fiscal policy shocks (deviations from policy rules) are estimated to have relatively small effects on the current account. We find interesting differences in Chilean and New Zealand responses to some shocks, despite similarities between the two economies and the common structural model employed.
\end{abstract}

JEL codes: E31, E32, F32, F41

Keywords: current account, commodity price, small open economy, DSGE model 



\section{Contents}

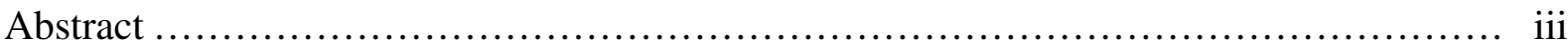

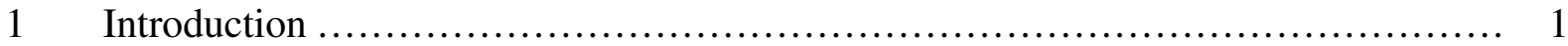

2 Current Account and macro framework evolution .............................. 2

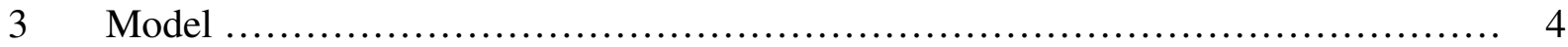

$3.1 \quad$ Households ............................................................ 4

3.1.1 Consumption-savings decisions by Ricardian households .............. 5

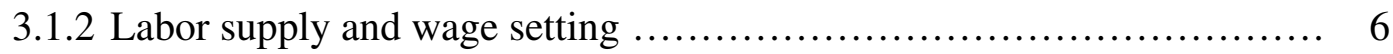

3.1.3 Non-Ricardian households ...................................... 7

3.2 Investment and capital goods........................................... 7

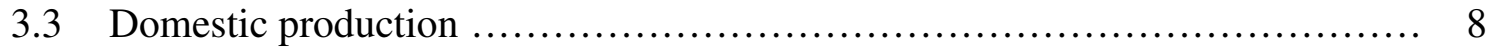

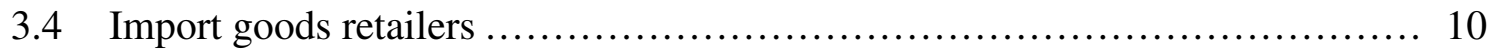

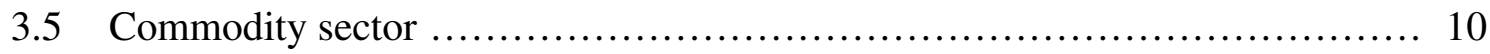

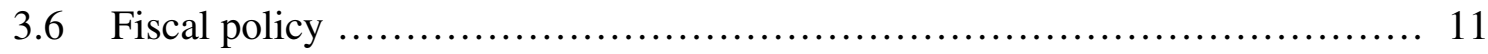

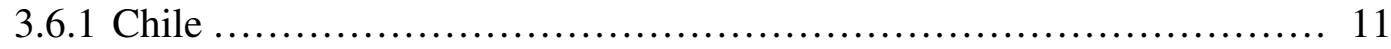

3.6.2 New Zealand...................................................... 12

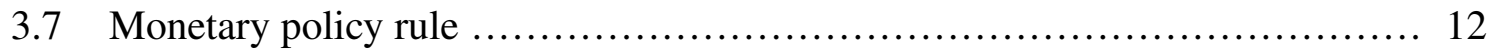

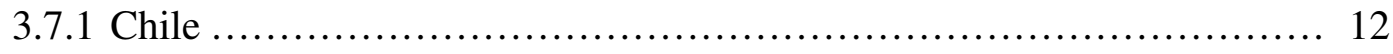

3.7.2 New Zealand.................................................... 13

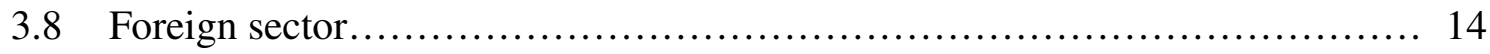

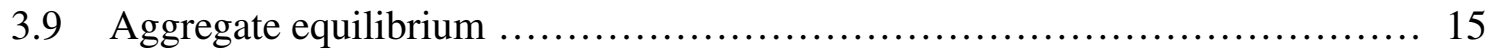

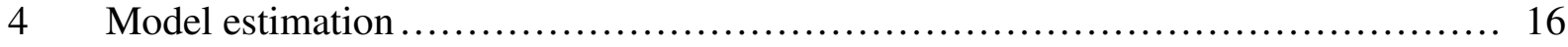

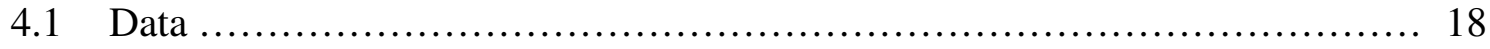

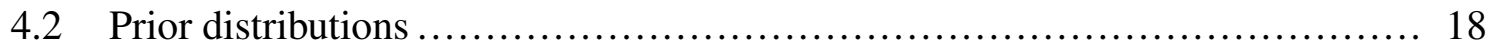

4.3 Posterior distributions .............................................. 20

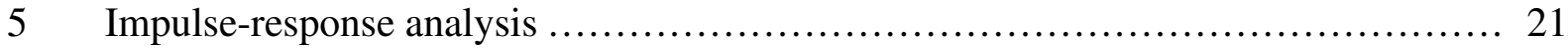

6 What drives the current account in Chile and New Zealand? ....................... 24

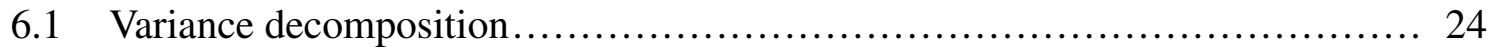

6.2 Historical decomposition of the current account .......................... 26

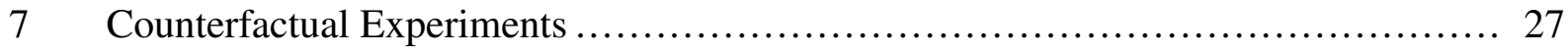

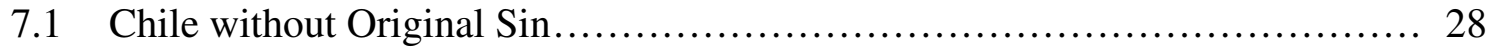

7.2 The Effect of a More or Less Aggressive Monetary Policy in New Zealand ..... 28

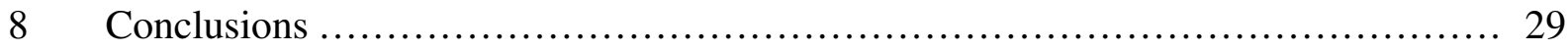

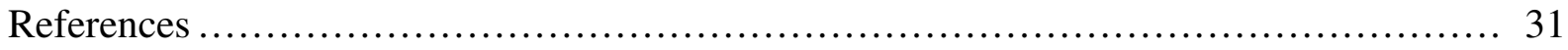





\title{
What drives the Current Account in Commodity Exporting Countries? The cases of Chile and New Zealand
}

\author{
Juan Pablo Medina, Anella Munro and Claudio Soto ${ }^{1}$
}

\section{Introduction}

As capital markets have become more integrated, savings and investment within countries have tended to become less correlated (Feldstein-Horiokia 1980), with the corollary that savingsinvestment gaps, i.e. current accounts, have tended to become more variable. There has also been a trend toward larger gross external asset and liability positions relative to GDP, even where net positions have changed little (Lane and Milesi Ferretti 2006). The increase in both external stocks and external flows relative to income allows a more efficient matching of borrowers and savers, but it also creates risks for both macroeconomic and financial stability associated with swings in sentiment in financial markets.

Understanding the main domestic and external factors that drive variations in the external accounts is a starting point for assessing the risks of financial and macroeconomic disruption that might be associated with changes in external flows. We observe the current account from three "reduced form" perspectives: (i) as current account transactions e.g., imports, exports and returns on debt and equity, (ii) as cross border financial transactions, and (iii) as the domestic savings-investment gap. None of these three "reduced form" views that we observe, however, tells us about causality, or about the endogenous interactions among factors such as interest rates, exchange rates, savings and investment. To understand the underlying driving forces, we need a structural model.

This paper uses an estimated open economy DSGE model with a commodity sector and nominal and real rigidities to ask what factors account for current account developments in two small commodity-exporting countries. Seven domestic shocks and three external shocks are considered to explain current account fluctuations. These include variations in foreign financial conditions, foreign demand, export commodity prices, productivity and investmentspecific shock and macroeconomic policy. We estimate the model on Chilean and New Zealand data, and investigate the factors that explain the similarities and differences in the behavior of the current account between these two countries.

The paper extends previous work on current account dynamics in the two countries. Munro and Sethi (2006) look at the current account from the perspective of a simple one shock consumption smoothing model and find that the data reject the cross equation restrictions implied by that model. Munro and Sethi 2007 examine current account dynamics in New Zealand using a fourshock model with a richer structure and find that foreign shocks account for half or more of current account variance. That model does not feature commodity prices, or monetary policy. The model employed here provides a richer structure for exploring current account dynamics in New Zealand and is the first structural study of current account dynamics in Chile.

By estimating a very similar model for both countries, we are able to better understand which features are country specific and which are model-specific. Chile and New Zealand share many

1 Prepared for the Tenth Annual Conference of the Central Bank of Chile "Current Account and External Financing”. Santiago, Chile, November 9th and 10th, 2006. We thank Juan Echavarria, Nicolas Eyzaguirre and Miguel Fuentes, Grant Spencer and conference participants for helpful discussion. All errors are our own. E-mail: Medina: Central Bank of Chile, jmedina@bcentral.cl; Munro: Bank for International Settlements, anella.munro@rbnz.govt.nz; Soto: Central Bank of Chile, csoto@bcentral.cl 
common features. They are both small open economies whose main exports are based on natural resources. Both economies have liberalised their trade and financial accounts. Chile implemented reforms in the 1970s, including trade and financial liberalisation, and during the 1990s it embraced a policy of bilateral trade agreements and the exchange rate was floated in 1999. ${ }^{2}$ New Zealand's external sector reforms were mainly concentrated in a short period from 1984 to 1987. Another common feature is the macroeconomic policy framework. The central banks of both countries gained autonomy in 1989, and both operate monetary policy in an inflation targeting framework. Both governments have a commitment to prudent fiscal policy.

Despite these similarities, there are still significant differences between these two countries. Per-capita income in New Zealand is more that twice that in Chile, and income distribution is more equal. In Chile, profits from commodity exports accrue to the Government and foreign investors, while in New Zealand, they accrue mainly to domestic private agents. New Zealand has faced large procyclical swings in immigration, which are not a relevant phenomenon in Chile. Lastly, and potentially importantly for understanding current-account developments, there are differences in the structure of external liabilities. New Zealand has a much larger net stock of external debt (70 per cent of GDP in 2005) than Chile (6 per cent of GDP in 2005). Somewhat offsetting the risks of a larger external debt, however, New Zealand has been able to issue external debt denominated in domestic currency, while Chile, like most emerging markets, still relies mainly on foreign-currency denominated debt.

In our estimated model, the main factors that account for fluctuations in the current accounts of both countries are investment-specific shocks, changes in foreign financial conditions (financial factors that affect the exchange rate), and variations in foreign demand. Fluctuations in commodity export prices have played a significant role in New Zealand's current account, but a smaller role in Chile where a large share of commodity revenue accrues to foreign investors. In both countries foreign shocks account for about half or more than half of the variation in the current account. Monetary and fiscal policy shocks (deviations from policy rules) are estimated to play a relatively small role in both countries.

The rest of the paper is organised as follows: the next section briefly describes current account developments in New Zealand and Chile over the last two decades. Section three presents the small open economy model used to characterise the main features of the Chilean and New Zealand economies. Model estimation is presented in section four, where we discuss the posterior distributions of key parameters. In section five, we analyze and compare the main transmission mechanisms implied by the model for both Chile and New Zealand, by examining the responses to different shocks. In section six we evaluate the importance of these shocks by presenting the variance decomposition and the historical decomposition of the current accounts. Section seven presents counterfactual experiments. Section eight concludes.

\section{Current Account and macro framework evolution}

This section briefly reviews current account developments in Chile and New Zealand and some of the main fundamentals that have featured in explaining them.

As shown in Figure 1, Chile's current account registered substantial deficits for three periods in the late 1980s, in 1993-95 and 1997-99, and has since moved into surplus. The unwinding of the deficit in the late 1980s reflected a sharp rise in savings despite a coincident rise in

2 After the crisis in 1982 some of the reforms were pulled-back. For instance, tariffs were increased between 1983 and 1985. During the 1990s, capital controls were introduced to slow down capital inflows. Those controls were removed in 1999. 
investment. It has been argued that the sharp rise in savings reflects the pension reform of 1981 that gradually introduced a fully-funded pension system (Bennett, Loayza and Schmidt- Hebbel, 2001; Morandé, 1998), and by the tax reform of 1984 (Agosín 1998).

The periods of current account deficit have generally coincided with periods of weak copper prices and have tended to be associated with a rising investment ratio. The deficits of the early 1990s also coincided with a surge in capital inflows to emerging market economies (Calvo, Leiderman, and Reinhart, 1996; Fernández-Arias and Montiel, 1996), associated to both "pull factors" (a buoyant domestic economy) and "push factors", (an increase in the appetite for investing in emerging markets economies). The systematic appreciation of the real exchange rate through the 1990s, the imposition of capital controls in 1991 and substantial reserves accumulation by the central bank may also have been factors affecting current account fuctuations during the period.

In 1998, there was a sharp improvement in Chile's current account position associated with a fall in investment, a shift seen in many emerging economies at the time. The more recent shift to a current account surplus has coincided with with a sharp rise in copper prices. The coincident rise in savings may be a result of the structural fiscal rule introduced in 2001, under which the government is committed to saving most of the windfall revenues associated with a high copper price.

As shown in Figure 1, New Zealand has run a persistent current account deficit throughout the period. The large average deficit is associated with interest and dividend payments on the large net stock external liabilities (about $85 \%$ of GDP). The investment income deficit has averaged about 6 per cent of GDP since 1990. On the trade side, rising commodity export prices tended to be associated with an improving current position in through the mid-1990s, but since then rising commodity export prices, if anything, have tended to be associated with growing deficits, contrary to what we might expect. In the last few years very high commodity export prices have been associated with large current account deficits, suggesting that other factors have been playing supporting import demand or discouraging exports. Periods of a strengthening New Zealand dollar have tended to coincide with a deteriorating current account in contrast to Chile, where exchange rate and current account fluctuations have been less (inversely) correlated.

A sustained fall in the rate of investment after the 1984 balance of payments crisis, has been followed by housing- led investment booms in the mid 1990s and after 2001. The savings rate dipped in the early 1990s, possibly associated with labour market reforms. The recent fall in savings has been associated with large increases in wealth from property price increases (Hodgetts et al, 2006). From a capital flow perspective, a feature of the recent deterioration has been large capital inflows associated with both offshore New Zealand bond issuance and the carry trade. These flows have put upward pressure on the exchange rate and have mainly been absorbed mainly by the household sector, which has increased debt from about 50 per cent of disposable income in 1990 to about 160 per cent in 2006. Concern about the strong exchange rate and large external imbalances has led to a review of the macroeconomic policy framework in New Zealand (Buckle and Drew 2006, Buiter 2006, Edwards 2006, Grenville 2006and Schmidt-Hebbel 2006).

A variety of foreign and domestic factors not shown in Figure 1 may also contribute to variations in the two country's current accounts. External factors include fluctuations in foreign demand, low foreign interest rates, global appetite for risk and the Asian crisis (after which the current account deficits contracted in both countries). On the domestic side, consumption smoothing behaviour, productivity shocks (which are difficult to measure without a structural framework), fiscal policy (fiscal responsibility acts have been introduced in both countries and Chile has adopted a structural fiscal rule), and monetary policy (in the early 1990s the Central Bank of 
Chile set targets for the current account deficit although they were rather loosely defined, see Massad 2003) have likely also played a role.

This paper aims to shed light on the roles of these factors in understanding fluctuations in the current account, and why two commodity exporting countries both facing strong commodity export prices and the same global environment should have such different current account positions at the end of our sample. Because the current account responds endogenously to a variety of fundamentals, a structural model provides a useful tool to try to disentangle these various influences.

\section{Model}

The section sets out the model economy. The model is a small open economy model in the spirit of Christiano et al (2005), Altig et al (2004), and Smets andWouters (2003a, 2003b) and closely follows Medina and Soto (2006a). There are two types of households in the economy. Ricardian (optimizing, forward-looking) households make choices about consumption and borrowing, and set wages. Non-Ricardian households consume all their labour income and neither save nor borrow. Production technology uses labor and capital, and is subject to two stochastic shocks: a transitory shock and a permanent shock to labor productivity which introduces a trend into the major aggregates. The economy grows at a constant rate gy in steady state. Domestic prices, import prices and wages are sticky (subject to nominal rigidities á la Calvo), with partial indexation to past inflation; and there are adjustment costs to investment, To be consistent with the features of both Chile and New Zealand, we include a commodity sector whose production is based on a natural resource endowment and is assumed to be completely exported. Monetary policy is conducted through a policy rule for the interest rate; and fiscal policy is conducted through a structural rule in the case of Chile and a balanced budget rule in the case of New Zealand.

\subsection{Households}

The domestic economy is inhabited by a continuum of households indexed by $j \in[0,1]$. The expected present value of the utility of household $j$ at time $t$ is given by:

$$
U_{t}(j)=E_{t}\left\{\sum_{i=0}^{\infty} \beta^{i} \zeta_{C, t+i}\left[\log \left(C_{t+i}(j)-\tilde{h} C_{t+i-1}\right)-\zeta_{L} \frac{l_{t+i}(j)^{1+\sigma_{L}}}{1+\sigma_{L}}+\frac{\zeta_{\mathcal{M}}}{\mu}\left(\frac{\mathcal{M}_{t+i}(j)}{P_{C, t+i}}\right)^{\mu}\right]\right\}
$$

where $C_{t}(j)$ is its total consumption, $C_{t}$ is aggregate per capita consumption $l_{t}(j)$ is labor effort, and $\mathcal{M}_{t}(j)$ corresponds to nominal balances held at the beginning of period $t . P_{C, t+i}$ is the consumption price index. The variable $\zeta_{C, t}$ is a consumption preference shock that follows an AR(1) process subject to i.i.d. innovations. Preferences display habit formation measured by parameter $\tilde{h}^{3}{ }^{3}$ The parameter $\sigma_{L}$ is the inverse real-wage elasticity of labor supply. The parameters $\zeta_{L}$ and $\zeta_{\mathcal{M}}$ are the weights of leisure and nominal balances in household preferences while $\mu$ defines the semi-elasticity of money demand to the nominal interest rate. The aggregate consumption bundle is given by the following constant elasticity of substitution

3 Since the economy grows in the steady state, we adjust the habit formation parameter in the preferences to $\tilde{h}=h\left(1+g_{y}\right)$ where $h$ corresponds to the habit formation parameter in an economy without steady-state growth. 
(CES) aggregator of home and foreign goods,

$$
C_{t}(j)=\left[\gamma_{C}^{1 / \eta_{C}}\left(C_{H, t}(j)\right)^{\frac{\eta_{C}-1}{\eta_{C}}}+\left(1-\gamma_{C}\right)^{1 / \eta_{C}}\left(C_{F, t}(j)\right)^{\frac{\eta_{C}-1}{\eta_{C}}}\right]^{\frac{\eta_{C}}{\eta_{C}-1}}
$$

where $\eta_{C}$ is the elasticity of substitution between home and foreign goods in the consumption bundle and $\gamma_{C}$ defines their respective weights. The optimal composition of this bundle is obtained by minimizing its cost. This minimization problem determines the demands for home and foreign goods by the household, $C_{H, t}(j)$ and $C_{F, t}(j)$ respectively, which are given by

$$
C_{H, t}(j)=\gamma_{C}\left(\frac{P_{H, t}}{P_{C, t}}\right)^{-\eta_{C}} C_{t}(j), \quad C_{F, t}(j)=\left(1-\gamma_{C}\right)\left(\frac{P_{F, t}}{P_{C, t}}\right)^{-\eta_{C}} C_{t}(j),
$$

where $P_{H, t}$ and $P_{F, t}$ are the price indices of home and foreign goods, and $P_{C, t}$ is the price index of the consumption bundle, defined as: $P_{C, t}=\left(\gamma_{C} P_{H, t}^{1-\eta_{C}}+\left(1-\gamma_{C}\right) P_{F, t}^{1-\eta_{C}}\right)^{\frac{1}{1-\eta_{C}}}$.

We consider two type of households: Ricardian households and non-Ricardian households. The first type make intertemporal consumption and savings decisions in a forward looking manner by maximizing their utility subject to their intertemporal budget constraint. In contrast, nonRicardian households consume their after-tax disposable income. This latter type of households receive no profits from firms and have no savings. We assume that a fraction $\lambda$ of households are non-Ricardian households.

\subsubsection{Consumption-savings decisions by Ricardian households}

Ricardian households have access to four types of assets: money $\mathcal{M}_{t}(j)$, one-period noncontingent foreign bonds (denominated in foreign currency) $B_{t}^{*}(j)$, one-period non-contingent foreign bonds (denominated in domestic currency) $B_{t}(j)$, and one-period domestic contingent bonds $\mathcal{D}_{t+1}(j)$ which pays out one unit of domestic currency in a particular state (state contingent securities). The budget constraint of households $j$ is given by:

$$
\begin{aligned}
P_{C, t} C_{t}(j)+E_{t}\left\{d_{t, t+1} \mathcal{D}_{t+1}(j)\right\}+\frac{\mathcal{E}_{t} B_{t}^{*}(j)}{\left(1+i_{f, t}^{*}\right) \Theta_{f}\left(\mathcal{B}_{t}\right)}+\frac{B_{t}(j)}{\left(1+i_{d, t}^{*}\right) \Theta_{d}\left(\mathcal{B}_{t}\right)}+\mathcal{M}_{t}(j)= \\
W_{t}(j) l_{t}(j)+\Pi_{t}(j)-\mathcal{T}_{p, t}+\mathcal{D}_{t}(j)+\mathcal{E}_{t} B_{t-1}^{*}(j)+B_{t-1}(j)+\mathcal{M}_{t-1}(j),
\end{aligned}
$$

where $\Pi_{t}(j)$ are profits received from domestic firms, $W_{t}(j)$ is the nominal wage set by the household, $\mathcal{T}_{p, t}$ is lump-sum net taxes paid to the government, and $\mathcal{E}_{t}$ is the nominal exchange rate (expressed as units of domestic currency per one unit of foreign currency). Variable $d_{t, t+1}$ is the period $t$ price of one-period domestic contingent bonds normalized by the probability of the occurrence of the state. Assuming the existence of a full set of contingent bonds ensures that consumption of all Ricardian households is the same, independent of the labor income they receive each period.

Variable $i_{f, t}^{*}$ is the interest rate on foreign bond denominated in foreign currency, and $i_{d, t}^{*}$ is the interest rate on foreign bond denominated in domestic currency. The terms $\Theta_{f}($.$) and \Theta_{d}($.$) are$ the premiums domestic households have to pay when they borrow from abroad, either in foreign or domestic currency. They are functions of the net foreign asset positions relative to GDP, $\mathcal{B}_{t}$, which is given by

$$
\mathcal{B}_{t}=\frac{\mathcal{E}_{t} B_{t}^{*}}{P_{Y, t} Y_{t}}+\frac{B_{t}}{P_{Y, t} Y_{t}}
$$


where $P_{Y, t} Y_{t}$ is nominal GDP, $B_{t}^{*}$ and $B_{t}$ are the foreign currency and domestic currency denominated aggregate net asset positions respectively. ${ }^{4}$

The fact that the premium depends on the aggregate net asset position -and not the individual position-implies that Ricardian households take it as an exogenous variable when optimizing. ${ }^{5}$ In the steady state we assume that $\Theta_{f}()=.\Theta_{f}$ and $\Theta_{d}()=.\Theta_{d}$ (constants), and that $\frac{\Theta_{f}^{\prime}}{\Theta_{f}} \mathcal{B}=\varrho_{f}$ and $\frac{\Theta_{d}^{\prime}}{\Theta_{d}} \mathcal{B}=\varrho_{d}$. When the country is a net debtor, $\varrho_{f}$ and $\varrho_{d}$ correspond to the elasticities of the upward-sloping supply of international funds.

Each Ricardian household chooses a consumption path and the composition of its portfolio by maximizing (1) subject to its budget constraint. The first order conditions on different contingent claims over all possible states define the following Euler equation for consumption:

$$
\beta E_{t}\left\{\left(1+i_{t}\right) \frac{P_{C, t}}{P_{C, t+1}} \frac{\zeta_{C, t+1}}{\zeta_{C, t}}\left(\frac{C_{t+1}(j)-\tilde{h} C_{t}}{C_{t}(j)-\tilde{h} C_{t-1}}\right)\right\}=1, \quad \text { for all } j \in(\lambda, 1]
$$

where we have used the fact that in equilibrium $1 / E_{t}\left[d_{t, t+1}\right]=1+i_{t}$, where $i_{t}$ is the domestic risk-free interest rate. From this expression and the first order condition with respect to foreign bonds denominated in foreign currency we obtain the following expression for the uncovered interest parity (UIP) condition:

$$
\frac{1+i_{t}}{\left(1+i_{f, t}^{*}\right) \Theta_{f}\left(\mathcal{B}_{t}\right)}=\frac{E_{t}\left\{\frac{P_{t}}{P_{t+1}} \frac{\mathcal{E}_{t+1}}{\mathcal{E}_{t}} \frac{\zeta_{C, t+1}}{\zeta_{C, t}}\left(\frac{C_{t+1}(j)-\tilde{h} C_{t}}{C_{t}(j)-\tilde{h} C_{t-1}}\right)\right\}}{E_{t}\left\{\frac{P_{t}}{P_{t+1}} \frac{\zeta_{C, t+1}}{\zeta_{C, t}}\left(\frac{C_{t+1}(j)-\tilde{h} C_{t}}{C_{t}(j)-\tilde{h} C_{t-1}}\right)\right\}} \quad \text { for all } j \in(\lambda, 1]
$$

Analogously, from the first order condition with respect to foreign bonds denominated in domestic currency we get the following parity condition:

$$
\frac{1+i_{t}}{\left(1+i_{d, t}^{*}\right) \Theta_{d}\left(\mathcal{B}_{t}\right)}=1
$$

These arbitrage conditions must hold independently of whether domestic agents are borrowing in domestic or foreign currency. The foreign interest rate is assumed to be unobservable and to follow an AR(1) process subject to i.i.d. shocks. These shocks to $i_{t}^{*}$ (which we call shocks to foreign financial conditions or UIP shocks) capture all foreign financial factors, including price, risk premia and any flow effects that influence the exchange rate.

\subsubsection{Labor supply and wage setting}

Each household $j$ is a monopolistic supplier of a differentiated labor service. There is a set of perfectly competitive labor service assemblers that hire labor from each household and combine it into an aggregate labor service unit,

$$
l_{t}=\left(\int_{0}^{1} l_{t}(j)^{\frac{\epsilon_{L}-1}{\epsilon_{L}}} d j\right)^{\frac{\epsilon_{L}}{\epsilon_{L}-1}}
$$

$4 \quad$ In our notation, $B_{t}^{*}=\int_{\lambda}^{1} B_{t}^{*}(j) d j$ and $B_{t}=\int_{\lambda}^{1} B_{t}(j) d j$.

5 This premium is introduced mainly as a technical device to ensure stationarity (see Schmitt-Grohé and Uribe, 2001). 
This labor unit is then used as an input in production of domestic intermediate varieties. Parameter $\epsilon_{L}$ corresponds to the elasticity of substitution among different labor services.

Following Erceg et al. (2000) we assume that wage setting is subject to a nominal rigidity à la Calvo (1983). In each period, each type of household faces a probability $1-\phi_{L}$ of being able to re-optimize its nominal wage. In this set-up, parameter $\phi_{L}$ is a measure of the degree of nominal rigidity. The larger is this parameter the less frequently wages are adjusted (i.e. the more sticky they are). We assume that all those households that cannot re-optimize their wages follow an updating rule considering a geometric weighted average of past CPI inflation, and the inflation target set by the authority, $\bar{\pi}_{t}$. Once a household has set its wage, it must supply any quantity of labor service demanded at that wage. A particular household $j$ that is able to re-optimize its wage at $t$ must solve the following problem:

$$
\max _{W_{t}(j)}=E_{t}\left\{\sum_{i=0}^{\infty} \phi_{L}^{i} \Lambda_{t, t+i}\left[\frac{\Gamma_{W, t}^{i} W_{t}(j)}{P_{C, t+i}} l_{t+i}(j)-\zeta_{L} \frac{l_{t+i}(j)^{1+\sigma_{L}}}{1+\sigma_{L}}\left(C_{t+i}-\tilde{h} C_{t+i-1}\right)\right]\right\}
$$

subject to labor demand and the updating rule for the nominal wage of agents who do not optimize defined by function $\Gamma_{W, t}^{i}{ }^{6}$ Variable $\Lambda_{t, t+i}$ is the relevant discount factor between periods $t$ and $t+i^{7}$

\subsubsection{Non-Ricardian households}

Since non-Ricardian households have no access to assets and own no shares in domestic firms, they consume all of their after-tax disposable income, which consists of labor income minus per-capita lump-sum taxes:

$$
C_{t}(j)=\frac{W_{t}}{P_{C, t}} l_{t}(j)-\frac{\mathcal{T}_{p, t}}{P_{C, t}}, \text { for } j \in[0, \lambda]
$$

For simplicity we have assumed that non-Ricardian households set wages equal to the average wage set by Ricardian households. Given the labor demand for each type of labor, this assumption implies that labor effort of non-Ricardian households coincides with the average labor effort by Ricardian households.

\subsection{Investment and capital goods}

There is a representative firm that rents capital goods to firms producing intermediate varieties. This firm decides how much capital to accumulate each period. New capital goods are assembled using a CES technology that combines home and foreign goods as follows:

$$
I_{t}=\left[\gamma_{I}^{1 / \eta_{I}} I_{H, t}^{1-\frac{1}{\eta_{I}}}+\left(1-\gamma_{I}\right)^{1 / \eta_{I}} I_{F, t}^{1-\frac{1}{\eta_{I}}}\right]^{\frac{\eta_{I}}{\eta_{I}-1}}
$$

6 All those that cannot re-optimize during $i$ periods between $t$ and $t+i$, set their wages at time $t+i$ to $W_{t+i}(j)=\Gamma_{W, t}^{i} W_{t}(j)$, where $\Gamma_{W, t}^{i}=\left(T_{t+i} / T_{t+i-1}\right)\left(1+\pi_{C, t+i-1}\right)^{\chi_{L}}\left(1+\bar{\pi}_{t+i}\right)^{1-\chi_{L}} \Gamma_{W, t}^{i-1}$ and $\Gamma_{W, t}^{0}=1 . T_{t}$ is a stochastic trend in labor productivity. This term in the updating rule prevents an increasing dispersion in the real wages across households along the steady-state balanced growth path.

7 Since utility exhibits habit formation in consumption the relevant discount factor is given by $\Lambda_{t, t+i}=$ $\beta^{i}\left(\frac{C_{t}-\tilde{h} C_{t-1}}{C_{t+i}-\tilde{h} C_{t+i-1}}\right)$. 
where $\eta_{I}$ is the elasticity of substitution between home and foreign goods, and where parameter $\gamma_{I}$ is the share of home goods in investment. The demands for home and foreign goods by the firm are given by

$$
I_{H, t}=\gamma_{I}\left(\frac{P_{H, t}}{P_{I, t}}\right)^{-\eta_{I}} I_{t}, \quad I_{F, t}=\left(1-\gamma_{I}\right)\left(\frac{P_{F, t}}{P_{I, t}}\right)^{-\eta_{I}} I_{t},
$$

where $P_{I, t}$ is the investment price index, given by $P_{I, t}=\left[\gamma_{I} P_{H, t}^{1-\eta_{I}}+\left(1-\gamma_{I}\right) P_{F, t}^{1-\eta_{I}}\right]^{\frac{1}{1-\eta_{I}}}$, and where $I_{t}$ is total investment.

The firm may adjust investment each period, but changing investment is costly. This assumption is introduced as a way to obtain more inertia in the demand for investment (see Christiano et al. (2005)). It represents a short-cut to more cumbersome approaches to model investment inertia, such as time-to-build.

Let $Z_{t}$ be the rental price of capital. The representative firm must solve the following problem:

$$
\max _{K_{t+i}, I_{t+i}} E_{t}\left\{\sum_{i=0}^{\infty} \Lambda_{t, t+i} \frac{Z_{t+i} K_{t+i}-P_{I, t+i} I_{t+i}}{P_{C, t+i}}\right\},
$$

subject to the law of motion of the capital stock,

$$
K_{t+1}=(1-\delta) K_{t}+\zeta_{I, t} S\left(\frac{I_{t}}{I_{t-1}}\right) I_{t}
$$

where $\delta$ is its depreciation rate. Function $S$ (.) characterizes the adjustment cost for investment. This adjustment cost satisfies: $S\left(1+g_{y}\right)=1, S^{\prime}\left(1+g_{y}\right)=0, S^{\prime \prime}\left(1+g_{y}\right)=-\mu_{S}<0$. The variable $\zeta_{I, t}$ is a stochastic shock that alters the rate at which investment is transformed into productive capital. A rise in $\zeta_{I}$ implies the same amount of investment generates more productive capital. ${ }^{8}$

The optimality conditions for the problem above are the following:

$$
\begin{gathered}
\frac{P_{I, t}}{P_{C, t}}=\frac{Q_{t}}{P_{C, t}}\left[S\left(\frac{I_{t}}{I_{t-1}}\right)+S^{\prime}\left(\frac{I_{t}}{I_{t-1}}\right) \frac{I_{t}}{I_{t-1}}\right] \zeta_{I, t}- \\
E_{t}\left\{\Lambda_{t, t+1} \frac{Q_{t+1}}{P_{C, t+1}}\left[S^{\prime}\left(\frac{I_{t+1}}{I_{t}}\right)\left(\frac{I_{t+1}}{I_{t}}\right)^{2}\right] \zeta_{I, t+1}\right\}, \\
\frac{Q_{t}}{P_{C, t}}=E_{t}\left\{\Lambda_{t, t+1}\left(\frac{Z_{t+1}}{P_{C, t+1}}+\frac{Q_{t+1}}{P_{C, t+1}}(1-\delta)\right)\right\} .
\end{gathered}
$$

These two equations simultaneously determine the evolution of the shadow price of capital, $Q_{t}$, and real investment expenditure.

\subsection{Domestic production}

There is a large set of firms that use a CES technology to assemble home goods using domestic intermediate varieties. These firms sell home goods in the domestic market and abroad. Let $Y_{H, t}$ be quantity of home goods sold domestically, and $Y_{H, t}^{*}$ the quantity sold abroad (denominated in

8 Greenwood et al. (2000) argue that this type of investment-specific shock is relevant for explaining business cycle fluctuations in the US. 
foreign currency). The demands for a particular intermediate variety $z_{H}$ by these assemblers are given by:

$$
Y_{H, t}\left(z_{H}\right)=\left(\frac{P_{H, t}\left(z_{H}\right)}{P_{H, t}}\right)^{-\epsilon_{H}} Y_{H, t}, \quad Y_{H, t}^{*}\left(z_{H}\right)=\left(\frac{P_{H, t}^{*}\left(z_{H}\right)}{P_{H, t}^{*}}\right)^{-\epsilon_{H}} Y_{H, t}^{*},
$$

where $P_{H, t}\left(z_{H}\right)$ is the price of the variety $z_{H}$ when used to assemble home goods sold in the domestic market, and $P_{H, t}^{*}\left(z_{H}\right)$ is the foreign-currency price of this variety when used to assemble home goods sold abroad. Variables $P_{H, t}$ and $P_{H, t}^{*}$ are the corresponding aggregate price indices. $\epsilon_{H}$ is the elasticity of substitution among varieties.

Intermediate varieties are produced by firms that have monopoly power in that variety. These firms maximize profits by choosing the prices of their differentiated good subject to the corresponding demands, and the available technology. Let $\mathbf{Y}_{H, t}\left(z_{H}\right)$ be the total quantity produced of a particular variety $z_{H}$. The available technology is given by

$$
\mathbf{Y}_{H, t}\left(z_{H}\right)=A_{H, t}\left[T_{t} l_{t}\left(z_{H}\right)\right]^{\eta_{H}}\left[K_{t}\left(z_{H}\right)\right]^{1-\eta_{H}},
$$

where $l_{t}\left(z_{H}\right)$ is the amount of labor utilized, and $K_{t}\left(z_{H}\right)$ is the amount of physical capital rented. Parameter $\eta_{H}$ defines their corresponding shares in production. Variable $A_{H, t}$ represents a stationary productivity shock common to all firms. The variable $T_{t}$ is a stochastic trend in labor productivity, given by

$$
\frac{T_{t}}{T_{t-1}}=\zeta_{T, t}
$$

The exogenous shocks to both types of technology process are given by

$$
A_{H, t}=A_{H, t-1}^{\rho_{a_{H}}} \exp \varepsilon_{a_{H}, t} \quad \zeta_{T, t}=\left(1+g_{y}\right)^{1-\rho_{T}} \zeta_{T, t-1}^{\rho_{T}} \exp \varepsilon_{T, t}
$$

where $\varepsilon_{a_{H}, t} \sim N\left(0, \sigma_{a_{H}}^{2}\right)$ and $\varepsilon_{T, t} \sim N\left(0, \sigma_{T}^{2}\right)$ are i.i.d innovations and the persistence of the shocks is governed by $\rho_{a_{H}}$ and $\rho_{T}$.

In every period, the probability that a firm receives a signal for adjusting its price for the domestic market is $1-\phi_{H_{D}}$, and the probability of adjusting its price for the foreign market is $1-\phi_{H_{F}}$. These probabilities are the same for all firms, independently of their history. If a firm does not receive a signal, it updates its price following a simple rule that weights past inflation and the inflation target set by the central bank. Thus, when a firm receives a signal to adjust its price for the domestic market it solves:

$$
\max _{P_{H, t}\left(z_{H}\right)} E_{t}\left\{\sum_{i=0}^{\infty} \Lambda_{t, t+i} \phi_{H_{D}}^{i} \frac{\Gamma_{H_{D}, t}^{i} P_{H, t}\left(z_{H}\right)-M C_{H, t+i}}{P_{C, t+i}} Y_{H, t+i}\left(z_{H}\right)\right\},
$$

subject to (12) and the updating rule for prices, $\Gamma_{H_{D}, t}^{i}$. Analogously, if the firm receives a signal to adjust optimally its price for the foreign market, then it solves:

$$
\max _{P_{H, t}^{*}\left(z_{H}\right)} E_{t}\left\{\sum_{i=0}^{\infty} \Lambda_{t, t+i} \phi_{H_{F}}^{i} \frac{\mathcal{E}_{t+i} \Gamma_{H_{F}, t}^{i} P_{H, t}^{*}\left(z_{H}\right)-M C_{H, t+i}}{P_{C, t+i}} Y_{H, t+i}^{*}\left(z_{H}\right)\right\},
$$

subject to (12) and the updating rule for firms that do not optimize prices defined by $\Gamma_{H_{F}, t^{9}}^{i}$ Given this pricing structure, the optimal path for inflation is given by a New Keynesian Philips

9 If the firm does not adjust its price for the domestic market between $t$ and $t+i$, then the price it charges at $t+i$ will be $P_{H, t+i}\left(z_{H}\right)=\Gamma_{H_{D}, t}^{i} P_{H, t}\left(z_{H}\right)$, where $\Gamma_{H_{D}, t}^{i}=\Gamma_{H_{D}, t}^{i-1}\left(1+\bar{\pi}_{t+i}\right)^{1-\chi_{H_{D}}}\left(P_{H, t+i} / P_{H, t+i-1}\right)^{\chi_{H_{D}}}$ and $\Gamma_{H_{D}, t}^{0}=1$. 
curve with indexation. In its log-linear form, Inflation depends on both last period's inflation, expected inflation next period and marginal cost.

The variable $M C_{H, t}$ corresponds to marginal costs of producing variety $z_{H}$, which are given by,

$$
M C_{H, t}=\frac{1}{\eta_{H}} W_{t} \frac{l_{t}\left(z_{H}\right)}{\mathbf{Y}_{H, t}\left(z_{H}\right)} .
$$

Given the constant return to scale technology available to firms, and the fact that there are no adjustment costs for inputs which are hired from competitive markets, marginal cost is independent of the scale of production. More precisely, $l_{t}\left(z_{H}\right) / \mathbf{Y}_{H, t}\left(z_{H}\right)$ is just a function of the relative price of inputs. Given this pricing structure, the optimal path for inflation is given by a New Keynesian Philips curve with indexation. Inflation depends on last period's inflation, expected inflation next period and real marginal cost.

\subsection{Import goods retailers}

We introduce local-currency price stickiness in order to allow for incomplete exchange rate pass-through into import prices in the short-run. This feature of the model is important in order to mitigate the expenditure switching effect of exchange rate movements for a given degree of substitution between foreign and home goods.

There is a set of competitive assemblers that use a CES technology to combine a continuum of differentiated imported varieties to produce a final foreign good $Y_{F}$. This good is consumed by households and used for assembling new capital goods. The optimal mix of imported varieties in the final foreign good defines the demands for each of them. In particular, the demand for variety $z_{F}$ is given by:

$$
Y_{F, t}\left(z_{F}\right)=\left(\frac{P_{F, t}\left(z_{F}\right)}{P_{F, t}}\right)^{-\epsilon_{F}} Y_{F, t},
$$

where $\epsilon_{F}$ is the elasticity of substitution among imported varieties, $P_{F, t}\left(z_{F}\right)$ is the domesticcurrency price of imported variety $z_{F}$ in the domestic market, and $P_{F, t}$ is the aggregate price of import goods in this market.

Importing firms buy varieties abroad and re-sells them domestically to assemblers. Each importing firm has monopoly power in the domestic retailing of a particular variety. They adjust the domestic price of their varieties infrequently, only when receiving a signal. The signal arrives with probability $1-\phi_{F}$ each period. As in the case of domestically produced varieties, if a firm does not receive a signal it updates its price following a "passive" rule. ${ }^{10}$ Therefore, when a generic importing firm $z_{F}$ receives a signal, it chooses a new price by maximizing the present value of expected profits:

$$
\max _{P_{F, t}(z F)} E_{t}\left\{\sum_{i=0}^{\infty} \Lambda_{t, t+i} \phi_{F}^{i} \frac{\Gamma_{F, t}^{i} P_{F, t}\left(z_{F}\right)-\mathcal{E}_{t+i} P_{F, t+i}^{*}\left(z_{F}\right)}{P_{C, t+i}} Y_{F, t+i}\left(z_{F}\right)\right\},
$$

If the firm does not adjust its price for the foreign market, then the price charged at $t+i$ will be $P_{H, t+i}^{*}\left(z_{H}\right)=$ $\Gamma_{H_{F}, t}^{i} P_{H, t}^{*}\left(z_{H}\right)$, where $\Gamma_{H_{F}, t}^{i}=\Gamma_{H_{F}, t}^{i-1}\left(P_{F, t}^{*} / P_{F, t-1}^{*}\right)^{1-\chi_{H_{F}}}\left(P_{H, t+i}^{*} / P_{H, t+i-1}^{*}\right)^{\chi_{H_{F}}}$ and $\Gamma_{H_{F}, t}^{0}=1$.

10 This "passive" rule is defined by $\Gamma_{F, t}^{i}=\Gamma_{F, t}^{i-1}\left(1+\bar{\pi}_{t+i}\right)^{1-\chi_{F}}\left(P_{F, t+i} / P_{F, t+i-1}\right)^{\chi_{F}}$ and $\Gamma_{F, t}^{0}=1$ where $\chi_{F}$ is the share of non-optimising firms that index to last period's inflation and $\left(1-\chi_{F}\right)$ is the share that index to the inflation target. 
subject to the domestic demand for variety $z_{F}$ (16) and the updating rule for prices. For simplicity, we assume that $P_{F, t}^{*}\left(z_{F}\right)=P_{F, t}^{*}$ for all $z_{F}$.

In this setup, the optimal path for imported goods inflation is given by a New Keynesian Philips curve with indexation. Imported goods inflation has a backward-looking component, a forwardlooking component and depends on the marginal cost of imports at the dock. Changes in the nominal exchange rate will only partially passed through into prices of imported good sold domestically. Therefore, exchange rate pass-through will be incomplete in the short-run. In the long-run firms freely adjust their prices, so the law-of-one-price holds up to a constant.

\subsection{Commodity sector}

We assume that a single firm produces a homogenous commodity good that is completely exported abroad. Production evolves with the same stochastic trend as other aggregate variables and requires no inputs:

$$
Y_{S, t}=\left[\frac{T_{t}}{T_{t-1}} Y_{S, t-1}\right]^{\rho_{y_{S}}}\left[T_{t} Y_{S, 0}\right]^{1-\rho_{y_{S}}} \exp \left(\varepsilon_{y_{S}, t}\right)
$$

where $\varepsilon_{y_{S}, t} \sim N\left(0, \sigma_{y_{S}}^{2}\right)$ is a stochastic shock and $\rho_{y_{S}}$ captures the persistence of the shock to the production process. ${ }^{11}$ This sector is particularly relevant for the two economies, as it captures the developments in the copper sector in the case of Chile, and natural resources production in the case of New Zealand.

An increase in commodity production implies directly an increase in domestic GDP. Because there are no inputs, an increase in production comes as a windfall gain. It also may increase exports, if no counteracting effect on home goods exports dominates. We would expect that, as with any increase of technological frontier of tradable goods, a boom in this sector would induce an exchange rate appreciation. The magnitude of the appreciation would depend on the structural parameters governing the degree of intratemporal and intertemporal substitution in aggregate demand and production. Both countries are assumed to be price takers.

\subsection{Fiscal policy}

Let $B_{G, t}^{*}$ and $B_{G, t}$ be the net asset position of government in foreign and domestic currency, respectively. The evolution of the total the net position of the government is given by:

$$
\frac{\mathcal{E}_{t} B_{G, t}^{*}}{\left(1+i_{t}^{*}\right) \Theta\left(\frac{\mathcal{E}_{t} B_{t}^{*}}{P_{Y, t} Y_{t}}\right)}+\frac{B_{G, t}}{\left(1+i_{t}\right)}=\mathcal{E}_{t} B_{G, t-1}^{*}+B_{G, t}+\mathcal{T}_{t}-P_{G, t} G_{t},
$$

where $\left(1+i_{t}^{*}\right) \Theta($.$) is the relevant gross interest rate for government bonds denominated in$ foreign currency while $\left(1+i_{t}\right)$ is the one for government bonds denominated in domestic currency. Variable $G_{t}$ is government expenditure and $\mathcal{T}_{t}$ are total net fiscal nominal revenues (income tax revenues minus transfers to the private sector). For simplicity, we assume that the basket consumed by the government includes only home goods so that. $P_{G, t}=P_{H, t}$.

11 Production in this sector could be interpreted as the exogenous evolution of a stock of natural resources, and in the case of New Zealand, factors such as weather. In any increase in real output in response to a rise in commodity export prices will be captured in the production shock. 
Fiscal policy is defined by the four variables $B_{G, t}^{*}, B_{G, t} \mathcal{T}_{, t}$ and $G_{t}$. Therefore, given the budget constraint of the government, it is necessary to define a behavioral rule for three of these four variables.

Portfolio considerations can give rise of a preferable composition for the public asset holdings either in foreign and domestic currency. When agents are Ricardian, defining a trajectory for the primary deficit is irrelevant for the households decisions, as long as the budget constraint of the government is satisfied. On the contrary, when a fraction of the agents are non-Ricardian then the trajectory of the public debt and the primary deficit are relevant. In addition, the path of public expenditure may be relevant on its own as long as its composition differs from the composition of private consumption.

\subsubsection{Chile}

In the case of Chile we assume that a relevant fraction of households are non-Ricardian $(\lambda>0)$. Hence, the timing of the fiscal variables is relevant for the private sector. We also consider that public asset position is denominated in foreign currency. Fiscal revenues come from two sources: tax income from the private sector, which is a function of GDP, $\mathcal{T}_{p, t}=\left(\tau_{t} P_{Y, t} Y_{t}\right)$, and revenues from copper which are given by $P_{S, t} \chi Y_{S, t}$, where $\chi Y_{S, t}$ are copper sales from the state company. The parameter $\chi$ defines the domestic share of ownership in total copper production which, in turn, is assumed to be only public in the case of Chile. The variable $\tau_{t}$ corresponds to the average income tax rate.

More importantly, we consider that the Chilean government follows the structural balance fiscal rule (see Medina and Soto, 2006b). This implies that government expenditure as a share of GDP is given by the following expression:

$$
\begin{aligned}
\frac{P_{G, t} G_{t}}{P_{Y, t} Y_{t}}= & \left\{\left(1-\frac{1}{\left(1+i_{t-1}^{*}\right) \Theta_{t-1}}\right) \frac{\mathcal{E}_{t}}{\mathcal{E}_{t-1}} \frac{\mathcal{E}_{t-1} B_{G, t-1}^{*}}{P_{Y, t-1} Y_{t-1}} \frac{P_{Y, t-1} Y_{t-1}}{P_{Y, t} Y_{t}}+\right. \\
& \left.\tau\left(\frac{\bar{Y}_{t}}{Y_{t}}\right)+\mathcal{E}_{t} \bar{P}_{S, t}^{*} \chi \frac{Y_{S, t}}{P_{Y, t} Y_{t}}-\frac{B_{S, t}}{P_{Y, t} Y_{t}}\right\} \exp \left(\zeta_{G, t}\right)
\end{aligned}
$$

where $\bar{P}_{S, t}^{*}$ is the long-run ("reference") price of copper, $\bar{Y}_{t}$ is cyclically adjusted GDP and $\zeta_{G, t}$ is a shock that captures deviation of government expenditure from this fiscal rule. This shock follows an $\mathrm{AR}(1)$ process with i.i.d. innovations. The purpose of this fiscal rule is to avoid excessive fluctuations in government expenditure coming from transitory movements in fiscal revenues. For example, in the case of a transitory rise of fiscal revenues originated by copper price increases, the rule implies that this additional fiscal income should be mainly save. Notice that the level of public expenditure that is consistent with the rule includes interest payments. Therefore, if the net position of the government improves, current expenditure may increase.

\subsubsection{New Zealand}

In the case of New Zealand we assume that all households are Ricardian $(\lambda=0)$. Therefore, Ricardian equivalence holds and the particular mix of assets and liabilities that finance government absorption is irrelevant. For that reason, and without lost of generality, we abstract from government debt and assume that lump-sum taxes are adjusted in every period to keep the government budget balanced. Its expenditure follows a stochastic process given by

$$
G_{t}=\left[\frac{T_{t}}{T_{t-1}} G_{t-1}\right]^{\rho_{G}}\left[T_{t} G_{0}\right]^{\left(1-\rho_{G}\right)} \exp \left(\varepsilon_{g, t}\right),
$$


where $\varepsilon_{g, t} \sim N\left(0, \sigma_{g}^{2}\right)$ is an i.i.d. shock to government expenditure and $\rho_{G} \in(0,1)$ determines its persistence.

An important difference in the policy rule assumed for Chile from the rule for New Zealand is that the former allows for accumulation or de-accumulation of net assets by the government. However, the effects of a shock under either rule would be the same if all agents are Ricardian.

\subsection{Monetary policy rule}

\subsubsection{Chile}

Monetary policy in the case of Chile is characterized as a simple feedback rule for the real interest rate. Under the baseline specification of the model, we assume that the central bank responds to deviations of CPI inflation from target and to deviations of output from its trend. We also allow the central bank to react to deviations of the real exchange from a long-run level. This is meant to capture the fact that the central bank had a target for the exchange rate over most of the sample period. We approximate the monetary policy rule by:

$$
\frac{1+r_{t}}{1+r}=\left(\frac{1+r_{t-1}}{1+r}\right)^{\psi_{i}}\left(\frac{Y_{t}}{\bar{Y}_{t}}\right)^{\left(1-\psi_{i}\right) \psi_{y}}\left(\frac{1+\pi_{t}}{1+\bar{\pi}_{t}}\right)^{\left(1-\psi_{i}\right)\left(\psi_{\pi}-1\right)}\left(\frac{R E R_{t}}{R \bar{E} R}\right)^{\left(1-\psi_{i}\right) \psi_{r e r}} \exp \left(v_{t}\right)
$$

where $\pi_{t}=P_{C, t} / P_{C, t-1}-1$ is consumer price inflation and $\bar{\pi}_{t}$ is the inflation target set for period $t$, and $r_{t}=\left(1+i_{t}\right) /\left(P_{C, t} / P_{C, t-1}\right)-1$ is the net (ex-post) real interest rate. $\left(R E R_{t} / \overline{R E R}\right)$ is the deviation of real exchange rate deviations from its long-run level. Variable $v_{t}$ is a monetary policy shock that corresponds to a deviation from the policy rule and it is assumed to be an i.i.d. innovation. The parameter $\psi_{i}$ is the degree of interest rate smoothing and $\psi_{y}, \psi_{\pi}$ and $\psi_{\text {rer }}$ determine the responses to the output gap, the deviation of inflation from target and the real exchange rate respectively.

We define a rule in terms of the real interest rate to be consistent with the practice of the central bank during most part of the sample period used to estimate the model. ${ }^{12}$ As mentioned before, at the end of 1999 Chile adopted a fully-fledged inflation targeting framework and abandoned the target zone for the exchange rate. In order to capture this policy shift, we allow for a discrete change in the parameters of the monetary policy rule. Let $\varpi(t)$ be a vector containing the parameters of the monetary policy rule in period $t$. We assume that:

$$
\varpi(t)= \begin{cases}\varpi_{1}, & \text { if } t \leq 1999: \mathrm{Q} 4 \\ \varpi_{2}, & \text { if } t>1999: \mathrm{Q} 4\end{cases}
$$

Hence, $\varpi_{1}$ captures the value of the monetary policy coefficients for the first period of the sample and $\varpi_{2}$ for the second period. To be consistent with the adoption of the fully-fledged inflation targeting framework after 1999 , we impose $\psi_{\text {rer }, 2}=0$ for the second period. ${ }^{13}$

12 From 1985 to July 2001 the CBC utilized an index interest rate as its policy instrument. This indexed interest rate corresponds roughly to an ex-ante real interest rate (Fuentes et al., 2003).

13 This change in parameter values is assumed to be permanent and unanticipated. This means that when agents make decisions, they expect that these parameters will remain constant for ever. 


\subsubsection{New Zealand}

Monetary policy in New Zealand is characterized as a simple feedback rule for the nominal interest rate. The inflation target objective set out in the Policy Targets Agreement (PTA) between the Bank and the Government, is specified in terms of CPI inflation and a target band. As monetary policy influences the economy with a lag, this may be seen as an inflation forecast rule. ${ }^{14}$

Here the central bank is assumed to respond to deviations of CPI inflation from target (assumed to be 2 per cent for the period) and to deviations of output from its trend. ${ }^{15}$ The latter improves empirical fit and adds a degree of forward-lookingness to the rule without increasing the statespace of the model.

$$
\frac{1+i_{t}}{1+i}=\left(\frac{1+i_{t-1}}{1+i}\right)^{\psi_{i}}\left(\frac{Y_{t}}{\bar{Y}_{t}}\right)^{\left(1-\psi_{i}\right) \psi_{y}}\left(\frac{1+\pi_{t}}{1+\bar{\pi}_{t}}\right)^{\left(1-\psi_{i}\right) \psi_{\pi}} \exp \left(v_{t}\right)
$$

As in the case of Chile, $\pi_{t}$ is the inflation rate measured by the consumer price index, $\bar{\pi}_{t}$ is the inflation target for period $t$, and $v_{t}$ is a monetary policy shock which it is assumed to be an i.i.d. innovation.

\subsection{Foreign sector}

Foreign agents demand both the commodity good and home goods. The demand for the commodity good is completely elastic at the international price $P_{S, t}^{*}$. The law of one price holds for this good. Therefore, its domestic-currency price is given by,

$$
P_{S, t}=\mathcal{E}_{t} P_{S, t}^{*},
$$

We assume that the real price of the commodity good abroad, $\operatorname{Pr}_{S, t}^{*}=P_{S, t}^{*} / P_{t}^{*}$ follows an autoregressive process of order one. The variable $P_{t}^{*}$ is the foreign price index, i.e., the price of a "representative" bundle abroad.

The real exchange rate is defined as the relative price of the foreign "representative" bundle and the price of the consumption bundle in the domestic economy:

$$
R E R_{t}=\frac{\mathcal{E}_{t} P_{F, t}^{*}}{P_{C, t}}
$$

14 The policy rule in the Bank's forecasting model features inflation 6 to 8 quarters ahead. The PTA also requires the Bank to avoid unnecessary instability in output, interest rates and the exchange rate. The Bank did explicitly respond to exchange rate developments in 1996-1998 when a monetary conditions index was used to guide policy between forecast rounds. However, several papers suggest that including the exchange rate in the rule gains little, even if the exchange rate is included in the loss function, because of unfavorable volatility tradeoffs. See West (2003). The gain in empirical fit from including the exchange rate in the rule is small.

15 In practice, the target has changed over the period. Initially it was set at 0 to 2 per cent, and later changed to 0 to 3 percent and then 1 to 3 per cent. 
Foreign demand for the home good depends on its relative price and the total foreign aggregate demand, $Y_{t}^{*}$ :

$$
Y_{H, t}^{*}=\gamma^{*}\left(\frac{P_{H, t}^{*}}{P_{F, t}^{*}}\right)^{-\eta^{*}} Y_{t}^{*},
$$

where $\gamma^{*}$ corresponds to the share of domestic intermediate goods in the consumption basket of foreign agents, and $\eta^{*}$ is the price elasticity of demand. This demand function can be derived from a CES utility function with an elasticity of substitution across varieties equal to $\eta^{*}$. Foreign output is assumed to have a stochastic trend similar to the one in the domestic economy.

$$
Y_{t}^{*}=\left[\frac{T_{t}}{T_{t-1}} Y_{t-1}^{*}\right]^{\rho_{Y^{*}}}\left[T_{t} Y_{0}^{*}\right]^{1-\rho_{Y^{*}}} \exp \left(\varepsilon_{Y^{*}, t}\right)
$$

where $\varepsilon_{Y^{*}, t} \sim N\left(0, \sigma_{Y^{*}}^{2}\right)$ is a shock to foreign output and $\rho_{Y^{*}} \in(0,1)$ determines its persistence.

\subsection{Aggregate equilibrium}

Firms producing varieties must satisfy demand at the current price. Therefore, the market clearing condition for each variety implies that:

$$
\mathbf{Y}_{H, t}\left(z_{H}\right)=\left(\frac{P_{H, t}\left(z_{H}\right)}{P_{H, t}}\right)^{-\epsilon_{H}} Y_{H, t}+\left(\frac{P_{H, t}^{*}\left(z_{H}\right)}{P_{H, t}^{*}}\right)^{-\epsilon_{H}} Y_{H, t}^{*}
$$

where $Y_{H, t}=C_{H, t}+I_{H, t}+G_{t}$, and where $Y_{H, t}^{*}$ is defined in (23). Equilibrium in the labor market implies that total labor demand by producers of by intermediate varieties must be equal to labor supply: $\int_{0}^{1} l_{t}\left(z_{H}\right) d z_{H}=l_{t}$.

Since the economy is open and there is no international reserves accumulation by the central bank and no capital transfers, the current account is equal to the financial account. We differentiate the case of Chile and New Zealand. For Chile, we assume that all debt is denominated in foreign currency. For the case of New Zealand we assume that all foreign debt is denominated in domestic currency. Hence, the net foreign asset position to GDP ratio, $\mathcal{B}_{t}$ for each country is given by:

$$
\mathcal{B}_{t}=\left\{\begin{array}{ll}
\frac{\mathcal{E}_{t} B_{t}^{*}}{P_{Y, t} Y_{t}} & \text { in the case of Chile } \\
\frac{B_{t}}{P_{Y, t} Y_{t}} & \text { in the case of New Zealand }
\end{array} .\right.
$$

Using the equilibrium conditions in the goods and labor markets, and the budget constraint of households and the government, we obtain the following expression for the evolution of the net foreign asset position in the case of Chile:

$$
\frac{\mathcal{B}_{t}}{\left(1+i_{f, t}^{*}\right) \Theta_{f}\left(\mathcal{B}_{t}\right)}=\frac{\mathcal{E}_{t-1}}{\mathcal{E}_{t}} \frac{P_{Y, t-1} Y_{t-1}}{P_{Y, t} Y_{t}} \mathcal{B}_{t-1}-(1-\chi) \frac{P_{S, t} Y_{S, t}}{P_{Y, t} Y_{t}}+\frac{P_{X, t} X_{t}}{P_{Y, t} Y_{t}}-\frac{P_{M, t} M_{t}}{P_{Y, t} Y_{t}},
$$

where $\chi$ is the share of the domestic agents (only government in the case of Chile) in the revenues from the commodity sector $((1-\chi)$ is the share of foreigners $)$ and $P_{Y, t} Y_{t}=P_{t} C_{t}+$ $P_{H, t} G_{t}+P_{I, t} I_{t}+P_{X, t} X_{t}-P_{M, t} M_{t}$ is the nominal GDP - measured from demand side. Nominal imports and exports are given by $P_{M, t} M_{t}=\mathcal{E}_{t} P_{F, t}^{*} Y_{F, t}$ and $P_{X, t} X_{t}=\mathcal{E}_{t}\left(P_{H, t}^{*} Y_{H, t}^{*}+P_{S, t}^{*} Y_{S, t}\right)$, respectively. 
Analogously, we obtain the following expression for the evolution of the net asset position of New Zealand:

$$
\frac{\mathcal{B}_{t}}{\left(1+i_{d, t}^{*}\right) \Theta_{d}\left(\mathcal{B}_{t}\right)}=\frac{P_{Y, t-1} Y_{t-1}}{P_{Y, t} Y_{t}} \mathcal{B}_{t-1}-(1-\chi) \frac{P_{S, t} Y_{S, t}}{P_{Y, t} Y_{t}}+\frac{P_{X, t} X_{t}}{P_{Y, t} Y_{t}}-\frac{P_{M, t} M_{t}}{P_{Y, t} Y_{t}}
$$

Notice that in the case of Chile, changes in the nominal exchange rate directly affect the net foreign asset position when measured in domestic currency through valuation effects, while in the case New Zealand those valuation effects are not present. In other words, in the external asset position, the risk of devaluation is held by domestic agents in the case of Chile while it is held by foreign investors in the case of New Zealand. Therefore, the transmission mechanism for monetary policy - and other shocks - works differently in both countries.

\section{Model estimation}

The model is estimated using Bayesian methods (see DeJong, Ingram, and Whiteman (2000), Fernández-Villaverde and Rubio-Ramírez (2007), and Lubik and Schorfheide (2005)). ${ }^{16}$ The Bayesian methodology is a full information approach to jointly estimate the parameters of the DSGE model. The estimation is based on the likelihood function obtained from the solution of the log-linear version of the model. Prior distributions for the parameters of interest are used to incorporate additional information into the estimation. ${ }^{17}$

The log-linear version of the model developed in the previous section form a linear rational expectations system that can be written in canonical form as follows,

$$
\boldsymbol{\Gamma}_{0}(\vartheta) \mathbf{z}_{t}=\boldsymbol{\Gamma}_{1}(\vartheta) \mathbf{z}_{t-1}+\boldsymbol{\Gamma}_{2}(\vartheta) \varepsilon_{t}+\boldsymbol{\Gamma}_{3}(\vartheta) \xi_{t},
$$

where $\mathbf{z}_{t}$ is a vector containing the model variables expressed as log-deviation from their steadystate values. It includes endogenous variables and but the ten exogenous processes, $\zeta_{C, t}, i_{t}^{*}$, $\zeta_{T, t}, A_{H, t}, \zeta_{I, t}, Y_{S, t}, \operatorname{Pr}_{S, t}^{*}, \zeta_{G, t}\left(G_{t}\right.$ in the case of New Zealand), $v_{t}$, and $Y_{t}^{*}{ }^{18}$ In their log-linear form, each of these variables is assumed to follow an autoregressive process of order one. The vector $\varepsilon_{t}$ contains white noise innovations to these variables, and $\xi_{t}$ is a vector containing rational expectation forecast errors. The matrices $\boldsymbol{\Gamma}_{i}(i=0, \ldots, 3)$ are non-linear functions of the structural parameters contained in vector $\vartheta$. The solution to this system can be expressed as:

$$
\mathbf{z}_{t}=\mathbf{\Omega}_{z}(\vartheta) \mathbf{z}_{t-1}+\mathbf{\Omega}_{\varepsilon}(\vartheta) \varepsilon_{t},
$$

where $\Omega_{z}$ and $\Omega_{\varepsilon}$ are functions of the structural parameters. A vector of observable variables, $\mathbf{y}_{t}$, is related to the variables in the model through a measurement equation:

$$
\mathbf{y}_{t}=H \mathbf{z}_{t}+\mathbf{v}_{t}
$$

16 Fernández-Villaverde and Rubio-Ramírez (2004) and Lubik and Schorfheide (2005) discuss in depth the advantages of this approach to estimating DSGE models.

17 One of the advantages of the Bayesian approach is that it can cope with potential model mis-specification and possible lack of identification of the parameters of interest (Lubik and Schorfheide, 2005).

18 These variables correspond to a preference shock, a foreign interest shock, a stochastic productivity trend shock, a stationary productivity shock, an investment adjustment cost shock, a commodity production shock, a commodity price shock, a government expenditure shock, a monetary shock, and a foreign output shock, respectively. 
where $H$ is a matrix that relates elements from $\mathbf{z}_{t}$ with observable variables. $\mathbf{v}_{t}$ is a vector with i.i.d. measurement errors. Equations (27) and (28) correspond to the state-space form representation of the model. If we assume that the white noise innovations and measurement errors are normally distributed we can compute the conditional likelihood function for the structural parameters, $\vartheta$, using the Kalman filter, $L\left(\vartheta \mid \mathcal{Y}^{T}\right)$, where $\boldsymbol{y}^{T}=\left\{\mathbf{y}_{1}, \ldots, \mathbf{y}_{T}\right\}$. Let $\mathbf{p}(\vartheta)$ denote the prior density on the structural parameters. We can use data on the observable variables $\mathcal{Y}^{T}$ to update the priors through the likelihood function. The joint posterior density of the parameters is computed using Bayes' theorem

$$
\mathbf{p}\left(\vartheta \mid \mathcal{Y}^{T}\right)=\frac{L\left(\vartheta \mid \mathcal{Y}^{T}\right) \mathbf{p}(\vartheta)}{\int L\left(\vartheta \mid \mathcal{Y}^{T}\right) \mathbf{p}(\vartheta) d \vartheta}
$$

An approximated solution for the posterior distribution is computed using the MetropolisHastings algorithm (see Lubik and Schorfheide (2005)). The parameter vector to be estimated is $\vartheta=\left\{\sigma_{L}, h, \phi_{L}, \chi_{L}, \eta_{C}, \eta_{I}, \mu_{S}, \phi_{H_{D}}, \chi_{H_{D}}, \phi_{H_{F}}, \chi_{H_{F}}, \phi_{F}, \chi_{F}, \varpi^{\prime}, \eta^{*}, \varrho, \rho_{a_{H}}, \rho_{y_{S}}, \rho_{Y^{*}}, \rho_{i^{*}}, \rho_{\zeta_{C}}, \rho_{G}\right.$, $\left.\rho_{\zeta_{I}}, \rho_{T}, \sigma_{a_{H}}, \sigma_{y_{S}}, \sigma_{Y^{*}}, \sigma_{i^{*}}, \sigma_{m}, \sigma_{\zeta_{c}}, \sigma_{g}, \sigma_{\zeta_{I}}, \sigma_{\zeta_{T}}\right\} . \varpi$ is a vector with the parameters describing the monetary policy in both countries. For Chile, $\varpi^{\prime}=\left\{\psi_{i, 1}, \psi_{\pi, 1}, \psi_{y, 1}, \psi_{r e r, 1}, \psi_{i, 2}, \psi_{\pi, 2}, \psi_{y, 2}\right\}$. For New Zealand this vector of parameters consists of only $\left\{\psi_{i}, \psi_{\pi}, \psi_{y}\right\}$ (see Table 1). Other parameters of the model are not estimated but are chosen to match the steady-state of the model with long-run trends in the Chilean and New Zealand economies. Calibrated parameters are reported in Table 1.

For Chile, we assume annual long run labor productivity growth, $g_{y}$, of 3.5\%. ${ }^{19}$ The long-run annual inflation rate is set to $3 \%$, which is the midpoint target value for headline inflation defined by the CBC since 1999 . The subjective discount factor, $\beta$, is set to 0.995 (quarterly basis) to give an annual nominal interest rate of around $7.0 \%$ in the steady state. The share of home goods in the consumption and investment baskets, $\gamma_{C}$ and $\gamma_{I}$, are set to $70 \%$ and $40 \%$, respectively. These figures imply that investment is more intensive in foreign goods than consumption. The share of the commodity sector in total GDP is set to $10 \% .{ }^{20}$ The net export to GDP ratio, $\frac{X-M}{Y}$, in steady state is equal to $2 \%$ which is consistent with its average value over the sample period. The government share of commodity production, $\chi$, is set to $40 \%$ which is consistent with the average fraction of CODELCO (the state owned company) in the total production of copper in Chile. Consistent with the fact that Chile is a net debtor in the international financial markets, we calibrate the steady-state current account/GDP ratio to $-1.8 \%$.

For New Zealand, we assume annual long run labor productivity growth, $g_{y}$, of $1.5 \%$. The longrun annual inflation rate is set to $2 \%$, which is the midpoint target value for CPI inflation. The subjective discount factor, $\beta$, is set to 0.985 (annual basis) to give an annual real interest rate of around $3.0 \%$ in the steady state. The share of home goods in the consumption basket, $\gamma_{C}$, is $70 \%$ (the same as in Chile), but the share of home goods in the investment basket, $\gamma_{I}$, is lower at $25 \%$. So the investment response to changes in relative prices will be larger in the New Zealand case. The share of the commodity sector in total GDP is a little larger than in the Chilean case at $14 \% .^{21}$ The net export to GDP ratio, $\frac{X-M}{Y}$, in steady state is equal to $1.3 \%$ which is consistent with its average value over the sample period. In contrast to the Chilean case where ownership of commodity production is government and foreign, in New Zealand ownership of commodity

19 This is consistent with 5\% long run GDP growth and $1.5 \%$ of labor force growth.

20 Value-added of the mining sector accounts for $10 \%$ of total GDP in Chile.

21 This includes primary production plus some commodity based manufactures such as agricultural processing and pulp and paper 
production is mainly domestic private, $\chi=0.9$. Consistent with the fact that New Zealand has large net external liabilities, the investment income deficit is assumed to be about $-6.3 \%$ of GDP to give a steady-state current account/GDP ratio of $-5.0 \%$.

We calibrate some other parameters to make them consistent with previous empirical studies. The depreciation rate of capital is set to $6.8 \%$ for Chile and $8.0 \%$ for New Zealand on an annual basis. The production function of domestic producers is assumed to have labor share of about two thirds. We do not have country specific information on price and wage markups. Therefore, we use values consistent with those utilized by studies of other countries. In particular, we set $\epsilon_{L}=\epsilon_{H_{D}}=\epsilon_{H_{F}}=\epsilon_{F}=11 .{ }^{22}$ We use OLS estimates of the whole sample period for the underlying parameters governing the AR(1) process of commodity prices. The point estimate $\rho_{p_{S}^{*}}$ is 0.98 for the international copper price with a standard deviation equal to $8.5 \%$, and 0.99 for New Zealand's export commodity price index with a standard deviation of 3.5\%. Finally, we assume that monetary shocks are i.i.d., which implies that $\rho_{v}$ is zero. Finally, as mentioned before the fraction Ricardian household is set to $100 \%$ for New Zealand and $50 \%$ for Chile.

\subsection{Data}

To estimate the model we use Chilean quarterly data for the period 1990:Q1 to 2005:Q4. We choose the following observable variables: real GDP, $Y_{t}$, real consumption, $C_{t}$, real investment, $I N V_{t}$, real government expenditure/GDP ratio, $G_{t} / Y_{t}$, short-run real interest rate, $r_{t}$, a measure of core inflation computed by the Central Bank ("IPCX1") as a proxy for inflation, the real exchange rate, $\widehat{r e r}_{t}$, current account/GDP ratio, $\frac{C A_{t}}{P_{Y_{t}} Y_{t}}$, and real wages, $W_{t} / P_{C, t}$. We also include as an observable variable the international price of copper (in US dollars, deflated by a proxy of the foreign price index) as a proxy for the real price of the commodity good, $\widehat{p r}_{S, t}^{*}$. In total, we have ten observable variables. The inflation rate $\widehat{\pi}_{t}$ is expressed as deviation from its target. In the case of real quantities we use the first difference of the corresponding logarithm (except for government expenditure/GDP ratio):

$$
\mathbf{y}_{t}^{C H}=\left\{\Delta \ln Y_{t}, \Delta \ln C_{t}, \Delta \ln I N V_{t}, r_{t}, \widehat{\pi}_{t}, \widehat{r e r}_{t}, \frac{C A_{t}}{P_{Y, t} Y_{t}}, \frac{G_{t}}{Y_{t}}, \Delta \ln \left(\frac{W_{t}}{P_{C, t}}\right), \widehat{p r}_{S, t}^{*}\right\}
$$

The short-run real interest rate corresponds to the monetary policy rate. This was an indexed rate from the beginning of the sample until July 2001. After July 2001 the monetary policy has been conducted by using a nominal interest rate. Therefore, for the later period we construct a series for the real interest rate computing the difference between the nominal monetary policy rate and current inflation rate.

For New Zealand, we use quarterly data for the period 1989:Q2 to 2005:Q4. We choose the following observable variables: real GDP, real consumption, real investment, commodity production (primary production plus commodity-based processing), $Y_{S, t}$, short-run nominal interest rate, $\widehat{i}_{t}, \mathrm{CPI}$ inflation, the real exchange rate, current account/GDP ratio and real wages. We also include as observable variable the ANZ commodity export price index (in US dollars, deflated by the foreign price index) as a proxy for the real price of the commodity good. In total, we have ten observable variables.

22 Christiano et al (2005) use $\epsilon_{L}=21$ and $\epsilon_{H}=6$ for a closed economy model calibrated for US. Adolfson et al (2005) use the same values for an open economy model calibrated for Euro area. Brubakk et al (2005) use $\epsilon_{L}=5.5$ and $\epsilon_{H}=6$ for a calibrated model of the Norwegian economy. Jacquinot et al (2006) calibrate $\epsilon_{L}=2.65$ and $\epsilon_{H}=11$ for a model of the Euro Area. 
As in the case of Chile, real variables are expressed in first log difference and inflation as deviation from its target. The set of observable variables for New Zealand is the following:

$$
\mathbf{y}_{t}^{N Z}=\left\{\Delta \ln Y_{t}, \Delta \ln C_{t}, \Delta \ln I N V_{t}, \Delta \ln Y_{S, t}, \widehat{i}_{t}, \widehat{\pi}_{t}, \widehat{\operatorname{rer}}_{t}, \frac{C A_{t}}{P_{Y, t} Y_{t}}, \Delta \ln \left(\frac{W_{t}}{P_{C, t}}\right), \widehat{p r}_{S, t}^{*}\right\}
$$

The short-run nominal interest rate is the overnight interest rate (The Call Rate prior to March 1999 and the Official Cash Rate after March 1999). We subtract the inflation target from the nominal interest rate to make this variable stationary.

\subsection{Prior distributions}

Prior parameter density functions reflect our beliefs about parameter values. In general, we choose priors based on evidence from previous studies for Chile and New Zealand. When the evidence on a particular parameter is weak or non-existent we impose more diffuse priors by setting a relatively large standard deviation for the corresponding density function. Table 2 presents the prior distribution for each parameter contained in the parameter vector, $\vartheta$, its mean and an interval containing $90 \%$ of probability.

For the inverse elasticity of labor supply, $\sigma_{L}$, we assume a gamma distribution with mode equal to 1.0 and one degree of freedom. This implies that with $90 \%$ of probability $\sigma_{L}$ takes values between 0.05 and 3.0. This is a wide range and reflects the uncertainty we have regarding the value of this parameter. The habit formation parameter, $\tilde{h}$, is constrained to be between zero and one. We assume it has a beta distribution with mean 0.5 and a standard deviation of 0.25 . Therefore, a 90\% confidence interval for this coefficient lies between 0.1 and 0.9 . This range is much wider than the one considered by Adolfson et al (2005) for the same coefficient in the Euro area, reflecting again our uncertainty on the value for this parameter. The elasticity of substitution between home and foreign goods in consumption, $\eta_{C}$, and the elasticity of substitution between these goods in investment, $\eta_{I}$, are assumed to have an inverse gamma distribution with a unitary mode and 5 degrees of freedom. This implies that, with $90 \%$ of probability, each of these elasticities lie between 0.66 and 3.05. The price elasticity of foreign demand for domestic goods, $\eta^{*}$, has also an inverse gamma distribution with a unitary mode. For this parameter we choose 4 degrees of freedom to set our prior. This implies a relatively flat prior distribution: $90 \%$ of probability spans the range 0.64 and 3.66. These values are pretty much in line with Adolfson et al (2005).

The parameter $\mu_{S}$ has an inverse gamma distribution with mode 2.0 and 3 degrees of freedom. As a consequence, this parameter can take values between 1.3 and 9.8 with $90 \%$ of probability. This is a wide range reflecting, again, the uncertainty we have with respect to $\mu_{S}$. The elasticities of the international supply of funds, $\varrho_{f}$ and $\varrho_{d}$, are assumed to have an inverse gamma distribution with four degrees of freedom. For Chile, we assign a mode of 0.01 for these elasticities. For New Zealand we assume a deeper financial integration with the rest of the world, and in consequence, the mode of these elasticities is 0.001 .

The prior distributions of each parameter in the policy rule take into account values that have been reported in other empirical studies. ${ }^{23}$ In particular, the policy inertia parameter, $\psi_{i}$, has a beta distribution with a standard deviation of 0.10 . Previous estimation shows that the policy smoothing has been bigger in New Zealand than Chile. Hence, we assume a mean for $\psi_{i}$ equal to 0.70 and 0.75 for Chile and New Zealand, respectively. The combined parameter defining

23 For Chile, see Schmidt-Hebbel and Tapia (2002), Caputo (2005) and Céspedes, Ochoa and Soto (2005). For New Zealand, see Liu (2006) and Lubik and Schorfheide (2006). 
the policy response to inflation (when the policy instrument is the nominal interest rate), $\varphi_{\pi}$, has a gamma distribution with mode 1.50 and standard deviation equal to 0.15 for Chile and to 0.10 for New Zealand. These values are coherent with parameter $\varphi_{\pi}$ lying between 1.26 and 1.75 in the case of Chile with $90 \%$ of probability and between 1.34 and 1.67 in the case of New Zealand. The parameter defining the policy response to output, $\varphi_{y}$, also follows a gamma distribution with mean 0.5 and a standard deviation of 0.15 for Chile and 0.10 for New Zealand. In the case of Chile, we need to define a prior distributions for the reaction coefficient of interest rate to real exchange rate for the period $1990-99, \psi_{\text {rer }}$. This parameter has a gamma distribution with mean 0.2 and standard deviation equal to 0.1 .

Parameters defining the probability of resetting nominal wages and prices are assumed to have distributions bounded by the interval $[0,1]$ interval. The parameters $\phi_{L}, \phi_{H_{D}}, \phi_{H_{F}}$ and $\phi_{F}$ have beta distributions with means 0.75 and standard deviations of 0.1 . Those values imply that the probabilities of resetting nominal wages and prices can take values between 0.57 and 0.90 with $90 \%$ of probability. These numbers are coherent with wages and prices that can be optimally reset every 2.3 and 10 quarters. Parameters $\chi_{L}, \chi_{H_{D}}, \chi_{H_{F}}$ and $\chi_{F}$ have also beta distributions with means 0.50 and standard deviations of 0.25 . These distribution cover a range of values between 0.1 and 0.9 with $90 \%$ of probability. Hence, we do not impose very strong priors on the degree of inertia in wages and prices.

The autoregressive parameters of the stochastic shocks, $\rho_{a_{H}}, \rho_{y_{S}}, \rho_{y^{*}}, \rho_{\zeta_{L}}, \rho_{\zeta_{I}}, \rho_{i^{*}}, \rho_{\pi^{*}}, \rho_{\zeta_{F}^{*}}, \rho_{y_{S}}$, $\rho_{g}, \rho_{\zeta \Theta}$ have beta distributions. We do not impose tight priors on these distributions. For all these parameters we set the prior mean to 0.7 and the standard deviation to 0.20 . Therefore, with $90 \%$ probability, the values of these parameters lie between 0.32 to 0.96 . The variances of the shocks are assumed to be distributed as an inverse gamma with 3 degrees of freedom. This distribution implies diffuse priors for these parameters to reflect our uncertainty about the unobservable shock processes. The corresponding means and modes are set based on previous estimations and on trials with weak priors. In particular, $\sigma_{a_{H}}, \sigma_{\zeta_{C}}, \sigma_{\zeta_{L}}, \sigma_{\zeta_{I}}, \sigma_{C^{*}}, \sigma_{\zeta_{F}^{*}}, \sigma_{y_{S}}$ and $\sigma_{g}$ have a prior mode of 1.0 which implies, with $90 \%$ of probability, values between 0.64 and 4.89. For $\sigma_{i^{*}}$ the mode is set to 0.5 implying values that go from 0.32 to 2.45 , whereas for $\sigma_{\pi^{*}}$, $\sigma_{\zeta \Theta}$ and $\sigma_{v}$ the modes are set to $0.25,0.25$ and 0.20 , respectively.

\subsection{Posterior distributions}

Table 3 presents the mode of the posterior distributions of the parameters for Chile and New Zealand. Consistent with other studies, the degree of habit in consumption is a little higher for New Zealand at 0.81 than for Chile at 0.57 . The inverse elasticity of substitution for labour supply is very low for New Zealand. For Chile this eslasticiy is a little bit above other studies where only Ricardian households were considered.The elasticity of substitution for consumption is about 1.2 for both Chile and New Zealand, which is relatively low. The posterior estimate for the intra-temporal elasticity of substitution for investment is very close to the prior estimate and may not be well identified in the data. The price elasticity of foreign demand, $\eta^{*}$, is two in New Zealand compared to one in Chile. This means that exports respond more strongly to price signals (e.g. a currency depreciation) in New Zealand.

For Chile, wage rigidities are substantially lower than previous estimates. Wages are estimated to be reoptimized every 5 periods and only about 6 per cent of households that do not optimise are estimated to index wages to last period's inflation. The rest increase wages according to the central bank's 3 per cent inflation target. For New Zealand wages are estimated to be reoptimised less often at 11 quarters with about 10 percent of nonoptimising households indexing wages to last period's inflation, and the rest increasing wages according to the central bank's 2 per cent 
inflation target. The less frequent wage adjustment in New Zealand may reflect a higher degree of credibility on the monetary policy, which make costly adjustment to be less necessary.

Price rigidities in Chile are also lower than other estimates (Medina and Soto, 2006a; Caputo, Medina and Soto, 2006). Domestic prices are optimally adjusted frequently in both countries: on average every two quarters for Chile and every 3 quarters for New Zealand. The prices of home goods sold abroad are reoptimised much less frequently: on average every 29 quarters in Chile and every 12 quarters in New Zealand. Import prices are estimated to be reoptimised less frequently in New Zealand (30 quarters) compared to Chile (6 quarters), suggesting more local current pricing in New Zealand, but the degree of indexation of import prices is estimated to be much higher in Chile at 80 per cent.

Estimated monetary policy parameters are reasonable for both countries. For Chile we attempt to identify two policy rules: one for the period 1990-1999 and another for the period 2000-2005. In general the degree of interest rate smoothing and the responses to both inflation and output growth are estimated to be higher for New Zealand. These parameters are not, however, directly comparable because the policy rule is estimated in real terms in Chile and in nominal terms for New Zealand; and because the rule for the earlier period in Chile includes an exchange rate term. Nevertheless, it is interesting that the rule for the later period in Chile and the estimated New Zealand rule, both of which are characterised by pure inflation targeting, are quite similar (the interest rate smoothing parameters of 0.8 for Chile and 0.9 for New Zealand, the response to deviations of inflation from target are 1.6 and is 1.5; and the response to the deviation of output growth from steady state are estimated at 0.31 and 0.39 ).

The estimated volatility and persistence of the shocks are more similar than different. The only big difference in shock volatility is a much larger commodity production shocks in the case of Chile which likely reflects the fact that there is a single commodity rather than a basket in the case of New Zealand. Commodity production shocks are, however, less persistent in Chile (AR(1) coefficient of 0.64 compared to 0.91 for New Zealand) perhaps due to the agricultural nature of commodity production in New Zealand. In general, Chile appears to face more persistent domestic shocks. Investment specific shocks are estimated to be more persistent in Chile (AR(1) coefficient of 0.86 compared to 0.41 for New Zealand), as are labour productivity shocks (AR(1) coefficient of 0.99 compared to 0.16 for New Zealand) and to a lesser degree transitory productivity shocks (AR(1) coefficient of 0.90 compared to 0.69 for New Zealand).

\section{Impulse-response analysis}

To analyze the main transmission mechanisms implied by the model in this section we describe the effects of the shocks on the current account and some other variables for Chile and New Zealand. Figures 8 through 8 present the impulse responses to all the shocks in the model.

In the case of Chile two sets of results are shown: one for the responses under the policy rule prevailing before 2000 and the other for the responses under the rule in place estimated for 2000 to 2005. In the description below we emphasize a qualitative description of the effects of the shocks. In general, the differences under these two rules are mostly quantitative. We do not comment further on them.

Productivity and endowment shocks There are three productivity shocks, a permanent labour productivity shock that affects all firms, a transitory shock that affects domestic noncommodity production, and a transitory shock to commodity production - a "commodity endowment" shock. 
A permanent labour productivity shock increases output on impact, but not all the way to the new steady state level. ${ }^{24}$ This permanent productivity shock lowers the current account in both economies. Non-Ricardian households consume their additional income. Ricardian households anticipate higher future income and so increase consumption toward the new steady state level. Habit in consumption slows this adjustment. Similarly, firms anticipate higher profits in the future and expand their production by increasing their capital stocks. Again the adjustment is gradual due to investment adjustment costs. The increase in both consumption and investment draws in imports and leads to a deterioration of the current account. The relevance of this shock for current account dynamics has been emphasized recently by Aguiar and Gopinath (2007). They show that a standard real business cycle model for a small open economy requires a permanent productivity shock to generate the counter-cyclical current account behaviour observed in the data. The standard deviation of the permanent productivity shock is much larger in New Zealand (0.49) than in Chile (0.19).

In contrast, the transitory productivity shock has a larger standard deviation and is more persistent in Chile than in New Zealand. In both economies, this shock raises output (y), reduces employment and boosts real wages. The increase in productivity puts downward pressure on inflation (pic), and the real exchange rate (rer) initially depreciates in anticipation of lower interest rates. Labour falls to keep supply in balance with the slow expansion of aggregate demand (which is sluggish because of intertemporal smoothing in consumption, habit in consumption and investment adjustment costs). The monetary policy response to the shock is not very expansionary. In both countries, consumption (c) rises - although initially in Chile it decreases slightly due to the presence of non-Ricardian households, whose labor income falls. In Chile, investment (inv) increases as the marginal productivity of capital rises. After few quarters, however, it falls below its trend level. For New Zealand, the productivity shock is not persistent enough to induce an expansion in investment, and this variable falls below trend immediately after the shock. In both countries, the transitory output expansion coupled with consumption smoothing - and the fall in investment in the case of New Zealand - plus the expenditure switching effect induced by a temporary real depreciation of the exchange rate, lead to an improvement in the current account measured as fraction of GDP (ca_y).

A rise in the endowment of commodities (an exogenous increase in the commodity production) directly increases domestic GDP and exports, both in Chile and New Zealand. In Chile the shock is more volatile but less persistent than in New Zealand. The higher income expands aggregate demand leading to tighter monetary policy and real exchange rate appreciation. Consumption and investment also rise, and so do imports. However, the expansion of exports is larger and the current account improves in response to this shock in both economies.

Foreign shocks There are three foreign shocks: a commodity price shock, a foreign demand shock and a foreign interest rate shock. The commodity price shock is larger for Chile than for New Zealand (in Chile, it corresponds to a copper price shock while for New Zealand it is a shock to a broader commodity export price index). The shock is very persistent in both cases. For Chile, the shock implies a windfall revenue gain for the government and for foreign investors in copper production. Despite the intertemporal government consumption smoothing implied by the fiscal rule, the persistence of the shock leads the government to raise its expenditure on home goods, as its debt service falls. Also, the exchange rate appreciation reduces the value of foreign currency denominated debt and associated debt service cost allowing a further increase in expenditure. This expansion in aggregate demand

24 Note that the variables are detrended by labour productivity. e.g., a value of -0.5 would indicate that output has increased half way to the new steady state for a $1 \%$ permanent technology shock. 
raises output. Private consumption increases because of the increase in current income of nonRicardian households, and the effect of a rise in the overall wealth of the country on Ricardian consumption. The expansion in output increases the marginal product of capital, leading to a boom in investment. The increase in consumption and investment draw in imports, somewhat offsetting the effect of higher export values on the current account. In addition, the investment income balance deteriorates as $60 \%$ of the increase in copper sector proffts goes to foreign investors. Overall, the effect on the current account is positive, but much less persistent than in New Zealand.

In New Zealand the windfall is received by households which are assumed to own $90 \%$ of commodity export firms. Thus, the shock raises permanent income and consumption increases smoothly over time. The increase in consumption leads to a rise in output, upward pressure on inflation and a real exchange rate appreciation. Initially investment is low due to the monetary tightening, but later expands in reponse to the lower cost of (largely imported) investment goods. The positive effect of higher export values on the current account is moderated to some degree by a decline in export volumes, and increased imports due to higher domestic demand and substitution effects in response to the exchange rate appreciation. ${ }^{25}$ The higher cost of debt repayment in response to monetary tightening that follows the shock also dampens the effect on the current account. Overall the effect on the current account is still positive and more persistent than in the case of Chile. For both countries the trade balance measured at constant prices (tb_yr) declines as a consequence of the fall in exports and the increase in imports.

A foreign demand shock increases demand for home goods, and domestic production rises. In Chile, consumption of non-Ricardian households increases with income which increases domestic demand and puts upward pressure on domestic prices, and the monetary policy tightening leads to an exchange rate appreciation. The shock is persistent enough to increase investment to boost production, but only slowly due to adjustment costs, and the exchange rate appreciation reinforces this by reducing the cost of imported investment goods (investment is import intensive). Despite the increase in imports, the direct effect of foreign output on exports dominates and the current account improves in response to this shock. Ricardian agents respond only weakly to the transitory shock, and in New Zealand, consumption and investment fall as the depressive effect of a monetary tightening dominates. The effects on production, domestic demand and the exchange rate are substantially larger in Chile, but overall, the effect on the two current accounts is about the same.

A foreign interest rate shock, in our model, corresponds to a shock on the UIP condition. It captures not only movements in the (unobserved) foreign interest rate but also the unobserved currency risk premium and any capital flows that affect the exchange rate that are not reflected in observed interest rate differentials or the debt sensitive risk premium. The standard deviation of the shock is a four per cent real exchange rate movement in both countries, but plays out rather differently. First, in Chile exchange rate passthrough is higher ( $\mathrm{F}$ is lower and importers reoptimise every six quarters compared to every 31 quarters in New Zealand) so the depreciation has a larger effect on inflation. Second, in Chile, the degree of indexation in import prices $F$ is much higher, so inflationary pressure is persistent, leading to a larger monetary policy response. The monetary contraction depresses aggregate demand. In New Zealand this effect is muted by a high degree of local currency pricing (very infrequent reoptimisation and indexation mainly to the inflation target). Third, in New Zealand the price elasticity of foreign demand is estimated to

25 For New Zealand, the currency appreciation -"commodity currency" effect-is, however, smaller than that implied by reduced form estimates (here a $10 \%$ rise in commodity export prices leads to an exchange rate appreciation about $1.4 \%$, compared to 5 to $7 \%$ in reduced form estimates). The difference may be the result the covariance of world commodity prices with other factors such as world demand or the UIP shock. A larger commodity currency effect would reduce the positive effect of this shock on the current account. 
be higher so the expansion of exports is much larger. Finally, in Chile, the depreciation also leads to valuation effects: the domestic currency value of foreign currency liabilities increases leading to higher debt repayment which crowds out consumption and investment, further depressing aggregate demand

In both countries, this shock leads to a current account improvement: in Chile, more through a contraction of imports and in New Zealand, more through an expansion of exports. However the effect on GDP is opposite. In Chile a depreciation is contractionary and in New Zealand it is expansionary. While the usual suspect - the currency denomination of the debt - plays a role, pricing structures are also important.

Expenditure shocks A consumption preference shock leads to a consumption boom that raises output and increases demand for labor and capital inputs. It also pushes up inflation. The monetary policy response to the shock leads to an increase in the interest rate and appreciation of the real exchange rate. Despite the increase in the demand for capital, and a small fall in the cost of imports, the intertemporal substitution effect driven by the monetary policy response generates a contraction in investment. This shock leads to a deterioration of the current account. Initially, the rise in consumption stimulates imports. Exports fall because of the real appreciation of the currency. In the case of New Zealand, the fall in investment shortly dominates the boom in consumption so that imports fall below trend. This effect, however, is not strong enough to improve the current account. In the case of Chile, the fall in imports due to the contraction in investment leads to a slight improvement in the current account after several quarters.

In our model investment-specific shocks reduce the cost of transforming one unit of investment into one unit of capital. These shocks are estimated to be a little larger in New Zealand but more persistent in Chile. They lead to a boom in investment that increases output and employment. In the case of Chile, the increase in output raises current income and non-Ricardian household consumption surges. Therefore, despite the monetary contraction, total consumption also rises. In the case of New Zealand, since all households are assumed to be Ricardian, the monetary contraction leads to a fall in consumption. The fall in inflation in both countries (in Chile there is a slight increase in this variable right after the shock) is explained by the fall in the cost of investment. For both countries, the current account initially deteriorates, mainly due the investment-driven rise in imports. However, the increase in the capital stock eventually leads to higher production and higher exports, so that the current account balance moves above trend after a couple of years.

A government expenditure shock, in the case of Chile, corresponds to a deviation from the structural balance rule described before. It implies an impulse to aggregate demand that boosts output and employment, and raises inflation. The monetary policy response to the shock an increase in the interest rate - depresses investment and consumption despite the increase in consumption by non-Ricardian households. The shock also implies an appreciation of the exchange rate because of both the rise in the interest rate and the composition of government spending, which is biased towards home goods. Although the fiscal balance worsens in response to this shock, the contraction in private expenditure leads to a current account improvement. This current account improvement, however, is small in magnitude and not very persistent.

In the case of New Zealand, this expenditure shock also boosts output and the monetary policy response depresses consumption and investment. Since the government consumes only home goods whereas households consume both home and foreign goods, and also because investment utilizes foreign goods, the crowding out effect of public spending in New Zealand implies a short-run improvement in the current account. As monetary policy tightens and the interest rate increases, debt service also increases and the current account deteriorates. On a medium-run 
horizon, when the interest rate has eased, the current account improves again as a consequence of the fall in imports.

Monetary policy shock A monetary policy shock induces a contraction in aggregate demand (consumption and investment), output and employment. Inflation falls in response to both the contraction in activity and the appreciation of the currency which puts downward pressure on the price of imported goods. In both Chile and New Zealand, exports and imports fall in response to the monetary shock. The former, because of the appreciation of the currency and the later because of the contraction of consumption and investment. In the case of Chile, given the estimated elasticities of substitution and the calibrated shares of foreign goods in consumption and investment, the intertemporal positive effect of a contractionary monetary policy shock dominates its negative intratemporal effects. As a result, the current account improves. Several quarters after the shock, as imports pick up led by the recovery in investment and exports remain depressed, the current account deteriorates a little. In the case of New Zealand, the effect of this shock on the current account is ambiguous. On impact, the current account improves because of the contraction in imports. However, one quarter after the shock, it deteriorates. This is because New Zealand's foreign investment income depends on the domestic interest rate (see equations 5 and 26). The higher domestic interest rate due to tighter monetary policy implies larger debt service payments. So, despite an improvement in the trade balance, the current account falls. After some quarters, the trade balance effect dominates and the current account improves but it falls again as imports pick up while exports remain low.

\section{What drives the current account in Chile and New Zealand?}

We use the estimated model to tell a "story" about the evolution of the current account in both countries. We first discuss the variance decomposition of the current account, without conditioning on the historical evolution of the exogenous processes. We then use our identified shocks to show the contribution of each type of shock to the historical evolution of the current account of both countries over the sample period. It is worth noting that the variance and historical decompositions abstract from the steady state current account deficit, which is $1.8 \%$ of GDP in the case of Chile, and in the case of New Zealand, about 6 per cent of GDP.

\subsection{Variance decomposition}

Table 4 presents the variance decomposition of the current account for Chile and New Zealand. We group shocks in four categories as before: foreign shocks, domestic supply shocks (productivity shocks), domestic demand (expenditure) shocks and monetary shocks.

In both countries, foreign shocks explain about half or more than half of the variation in the current account at all horizons. For both countries, the most important foreign shock is the foreign interest rate shock (UIP shock). As discussed earlier, this shock includes fluctuations in the foreign interest rate, unobserved current risk premium and any capital flow effects that influence the exchange rate. This shock is very persistent in both countries (with estimated AR(1) coefficients of 0.985 in Chile and 0.923 in New Zealand) and has its main effect on the current account with a lag of about 2 years. It accounts for 58 to 71 per cent of current account variance at the 3 to 4 year horizon in Chile, and 40-44 per cent in New Zealand.

The foreign demand shock has a strong but transitory short term effect on the current account, accounting for about 40 per cent of current account variation in the first year after the shock. 
While the effects of these two shocks are similar, the effect of the third foreign shock, the commodity export price shock, is quite different in the two countries. In Chile a change in the copper price is estimated to have a short term effect, accounting for about two per cent of current account variation in the first year. This result goes against the the notion that Chile's current account fluctuates with the copper price. ${ }^{26}$ Part of the reason for this result is foreign ownership in the commodity sector. The positive effect on the trade balance is offset by an investment income deficit with 60 percent of copper sector profits accruing to nonresidents. A second reason is that, the (observed) copper price shock is positively correlated with the (unobserved) foreign demand shock, and in the context of the model, much of the variation in the improvement in the trade balance observationally associated with a copper price appreciation is attributed to foreign demand fluctuations.

In New Zealand, a change in the price of commodity exports has a larger and more medium term effect, accounting for 15 to 20 per cent of current account variation at the two and three year horizons. The difference likely reflects the different ownership structures, with the windfall gains going to private agents in New Zealand and to the government and foreign investors in Chile, and the fact that Chile's government has saved a large fraction of the windfall revenues from copper. ${ }^{27}$

Domestic supply and demand shocks in Chile account for about half of the remaining variation in the current account each, with monetary policy shocks accounting for very little. In New Zealand, domestic demand shocks are relatively more important, and again monetary policy shocks explain very little. The policy shocks are deviations from the policy rule, and the endogenous component of monetary policy - the parameterisation of the reaction function may be important.

The contribution of domestic demand shocks to variation in the current account mainly comes from the investment-specific shock. In Chile this accounts for 30 to 40 per cent of current account variation in the first two years, and in New Zealand for 40 per cent in the first year, with persistent effects at longer horizons. The importance of this shock suggests that a richer specification of the financial sector may help in understanding the investment specific factors at work. The contribution of domestic supply shocks is more broadly based. In Chile, commodity output fluctuations have important short term effects ( 17 to 20 per cent of the variance in the first year), and permanent labour productivity shocks have important longer term effects (16 to 20 per cent of current account variance in the third and fourth years). In New Zealand, variations in commodity production affect the current account with a similar magnitude, but with the main effect in the second year; and both permanent and transitory productivity shocks are important.

Government spending shocks are estimated to account for a small part of current account variance in both countries. In New Zealand, the effect is a little larger, and probably under stated a little due to our assumption that the government consumes only home goods. In the case of Chile, these shocks correspond to deviations by the government from the policy rule described previously. Therefore, they do not capture in full the effects of fiscal policy - broadly defined - on the evolution of the current account.

26 The variance decomposition is computed using the sample estimate of the variance of each shock. The recent copper price shock has been much larger than historical shocks. Therefore, the share of this shock in explaining the recent current account event is likely much higher. See the historical decomposition below.

De Gregorio (2006) argues that despite the structural balance rule, which was not in place before 2000, the government behaved very much as if the rule was already in place already during the 1990s. In fact, during most

of our sample period there existed a stabilization fund linked to the copper price that smoothed out the effects of shocks to this variable. 
Overall, the current account appears to be playing a positive shock absorber role in both countries, with respect to both foreign and domestic shocks. With an open capital account, households, in aggregate, can smooth consumption in the face of shocks by using foreign capital markets to borrow and lend, much as an individual uses a bank account.

\subsection{Historical decomposition of the current account}

In this subsection we highlight how some major developments are interpreted by the model, in terms of the model shocks, and the current account responses to those shocks. In Figures 8 and 8 we present the sample evolution of the identified shocks for Chile and New Zealand. Figures 8 and 8 present the historical contribution of each of them to the evolution of the current account for both countries.

Chile The evolution of the current account in Chile over the period is characterized by a phase of moderate deficits from 1990 until 1999-2000 and then by a period where the current account oscillated between small deficits and surpluses. The deficits observed at the beginning of the 1990s are explained mostly by a boom in investment, triggered by favorable domestic conditions, and by a weakness in foreign activity that depressed exports (Figure 8). The small improvement in the current account in 1995, according to the model, is explained by favorable external conditions that boosted exports. The average GDP of Chile's main trade partners grew by more than $4.5 \%$ in the year to March 1995 .

Foreign financial conditions also played an important role in explaining the evolution of the current account over the 1990s. From 1991 until 1999, easing foreign financial conditions large capital inflows - contributed to a growing current account deficit. The current account reversed dramatically in 2000, after the Asian crisis and coincidentally with Argentina's crisis. Notice, however, that the reversal in the current account began before the reversal in foreign financial conditions. During 1999 there was a dramatic negative investment shock that depressed investment and imports. While there was an important contractionary monetary shock in late 1998, the model does not attribute a large share of responsibility for the fall in investment to that shock.

Despite the fact that the country's interest rate spread has been falling, the model identifies tightening external financial conditions as one of the reasons why the current account improved after 2000. As mentioned above, the UIP shocks capture more than the observed movements in the foreign interest rate and the risk premium faced by the country. They also capture any change in market conditions that affect the exchange rate above and beyond what the UIP condition would predict. The decline in natural resources as a share of GDP and a small investment boom after 2002 would have lead to a current account deficit, had no other shock hit the economy. More recently, an export expansion triggered by more robust growth in trading partners, and the copper-price boom, explain the current account surpluses observed over recent quarters.

New Zealand From a policy perspective, the main features of interest are the recent deterioration of the current account from about 2.9 per cent of GDP in 2001 to 9.7 per cent per cent of GDP in June 2006, similarities and/or differences with the current account deterioration from 1992 to 1997, and the factors that led to an improvement in the current account between these periods.

As shown in Figure 8, in the context of our model, the most important factors driving the New Zealand current account over the estimation period have been the price of commodity exports, 
shocks to foreign demand, the effects of foreign financial conditions on the exchange rate and investment-specific shocks.

Perhaps the largest swings in the current account during the period have come from the investment-specific shock. In the model, a positive investment adjustment shock means that a given amount of investment is transformed more efficiently into productive capital, and so reduces the cost of capital. This shock may also capture effects such as collateral constraints that affect investment. Investment specific shocks were negative during the labour market reforms of the early 1990s (perhaps due to a fall in marginal cost or increase in the marginal product of labour), positive in the mid-1990s (a period of rising investment and a housing boom) and negative in the late 1990s (possibly related to the end of the domestic housing boom or foreign financial crises). This shock has had a relatively small effect on the recent current account deterioration compared to that in the mid-1990s. While both periods have been characterised by investment booms and a current account deterioration, the effects of foreign financial conditions (exchange rate movements not explained by domestic interest rates) are estimated to have been more important in recent years.

A fall in the cost of foreign financing, $i_{F}$, represents an appreciation of the New Zealand dollar. The estimated historical shocks show periods of New Zealand dollar strength in 1996 and in 2004-5, and weakness in 2000-2001. The foreign interest rate/UIP shock is not only persistent, but it has its main effect on the current account through the volumes of imports and exports with a lag of about 2 years. Thus, the weak NZ\$ of 2000-2001 had a positive influence on the current account balance in 2002-3 (see Figure 8). The lagged response implies that the strong NZ\$ seen in 2004-5 will continue to have a negative effect on the current account balance through 2007. Appreciation of the exchange rate after 2001 has been relatively important in the recent deterioration.

The estimated foreign demand shock shows weak foreign demand in the early 1990s (following recession in some trading partners), strong foreign demand through the rest of the 1990s and weak foreign demand after about 2001. The foreign demand shock has a strong, but transitory short term effect and so the effect on the current account follows a similar pattern. This shock appears to pick up the effect of government imports (in the model the government is assumed to consume only home goods). This is seen clearly in the two spikes in 1997 and 1999 that correspond to the import of two Navy frigates. There has been an expansion in government imports in the past year or two on a smaller scale so that the effect of foreign demand is likely to be overstated and government spending correspondingly understated.

The shock to the world price of commodity exports is estimated to have its main impact on the current account through the value of exports in the second year after the shock. The historical shocks follow a path similar to the path of commodity export prices, measured in foreign currency. As shown in Figure 8, the relatively low world price of commodity exports in 19982003 had a negative effect on the current account position, while the rise in commodity export prices in 2004-5 has had a positive effect on the current account position, much as one would expect, but has been dominated by other developments.

From 1997 to 2002, the main factors that are estimated to have led to an improvement in the current account position were the investment specific shock and the contribution of changes in foreign financial conditions to the depreciation of the New Zealand dollar.

\section{Counterfactual Experiments}

This section explores conterfactual experiments for the evolution of the current account of Chile and New Zealand. First, we analyze the dynamics of the estimated model under a scenario that 
eliminates Chile's original-sin problem, assuming that external debt is denominated completely in Chilean pesos rather than in foreign currency. Second, we explore whether a more or less aggressive monetary policy response in New Zealand would change the current account responses to different shocks.

\subsection{Chile without Original Sin}

According to Eichengreen, Hausmann, and Panizza (2005), if a country is unable to borrow abroad in its own currency, it suffers from so-called original sin. Chile faces this problem. Most of the country's debt is denominated in U.S. dollars, creating an aggregate currency mismatch on its balance sheet. Consequently, external shocks could be amplified in the domestic economy. To shed light on the macroeconomic implication of issuing debt in domestic currency, we explore the dynamics of the model under a scenario in which Chile's entire external debt is denominated in Chilean pesos.

The responses of the main aggregate variables for the estimated model for Chile assuming an external debt denominated in pesos are shown in figure 8. For purpose of comparison, these are plotted together with the impulse response functions of the original estimated model, in which the external debt is denominated in U.S. dollars. GDP is less sensitive to external shocks (namely, commodity price, foreign demand, and interest rate shocks) when the external debt is in Chilean pesos, although the difference is moderate. This result may indicate that eliminating the valuation effects in the foreign income investment of the current account would help isolate aggregate domestic demand from fluctuations in external conditions.

The model predicts that the responses of the current account to some supply shocks would be larger if the external debt was denominated in Chilean pesos. In particular, the improvement in the current after a transitory productivity shock is around 1 percent in the short run when the debt is denominated in pesos, whereas this response is small in the baseline estimation. Permanent productivity shocks would generate a more significant worsening in the current account surplus with a peso denomination of external debt. We also observe that when the external debt is in pesos, the required movement in the exchange rate to generate an adjustment in the current account would be smaller.

In terms of monetary policy, interest rate innovations become less effective in influencing the current account if the external debt is denominated in pesos. This response is similar to the one found in the estimated model for New Zealand. A domestic-currency denomination for the external debt makes foreign investment income more related to the domestic interest rate. Thus, a tighter monetary policy directly increases debt service payments, offsetting its impact on the trade balance.

\subsection{The Effect of a More or Less Aggressive Monetary Policy in New Zealand}

While we don't usually associate the current account with monetary policy, in an open economy tight monetary policy may spill demand into the current account ${ }^{28}$ by putting upward pressure on the exchange rate and providing cheap imports. The variance and historical decompositions in the previous sections attribute almost no role to monetary policy shocks in explaining the exchange rate and the current account. It is still possible, however, that the endogenous

28 The associated appreciation makes imports cheap and exports less competitive, so diverting resources to meet domestic demand. This assumes that the Marshall Lerner Robinson condition is satisfied. Our estimates of import and export demand elasticities suggest that this is the case. 
monetary policy response embodied in the reaction function may be relevant to the behavior of the exchange rate and the current account. There is a perception in some circles that the strong exchange rate, supported by high domestic interest rates, has been detrimental for exporters and is responsible for New Zealand's large imbalances. This suggests that a less aggressive monetary policy response might help moderate the effects of shocks on the current account dynamics. Others argue that, to avoid large exchange rate fluctuations, monetary policy should aim to avoid being out of phase with the foreign business cycle, suggesting that a more aggressive monetary policy response is appropriate. The experiments in this subsection address these opposing claims. We conduct the two counterfactual experiments by adjusting the interest-ratesmoothing parameter. The results are shown in figure 8 .

First, we increase the smoothing parameter from the estimated 0.90 to 0.95 , which heightens the degree of smoothing and correspondingly softens the response to inflation and output. Since the estimated smoothing parameter is already high, the differences are not great. We are most interested in the shocks that account for the bulk of current account and exchange rate variance: namely, the foreign interest rate, investment cost, foreign output, and commodity price shocks. In the face of a foreign cost of capital (UIP) shock, which accounts for the bulk of exchange rate variance, there is hardly any difference in the exchange rate response. The current account responds a little later and is more persistent. The less aggressive response slightly reduces exchange rate volatility in the other three cases, while the effect on the current account is small.

Second, we reduce the degree of smoothing to 0.60 , implying a substantially stronger monetary response to inflationary pressure and output fluctuations in an effort to aggressively stabilize the business cycle. In the face of a foreign cost of capital (UIP) shock (which accounts for the bulk of exchange rate variance), there is almost no difference in the real exchange rate response. For the other three shocks of interest, the more aggressive monetary policy response increases real exchange rate volatility. The effect on the current account works mainly through the effect of sharper interest rate movements on the investment income account. In the case of a commodity price shock and a foreign output shock, the deterioration works to offset the improvement in the trade balance. For the investment-specific shock, the investment income deterioration reinforces the trade balance deterioration.

\section{Conclusions}

This paper used an open economy DSGE model with a commodity sector and nominal and real rigidities to ask what factors account for current account developments in two small commodity exporting countries. From a policy perspective, we are interested in understanding these factors to better understand the macroeconomic and financial stability risks associated with the increase in both external stocks and external flows relative to income associated with financial market integration, and the role of policy.

The model was estimated, using Bayesian techniques, on Chilean and on New Zealand data. The structural factors that explain the behavior of the current account were fairly similar for the two countries. We find that foreign financial conditions, investment-specific shocks, and foreign demand account for the bulk of the variation of the current accounts of the two countries. Monetary and fiscal policy shocks (deviations from policy rules) are estimated to have relatively small effects. For New Zealand, fluctuations in export commodity prices have also been important to explain the current account.

In both countries foreign shocks account for about half, or more than half, of current account variation at horizons up to 4 years. The most important contributions The most important contribution to current account movements was variations in foreign financial conditions, a 
combination of the effects of the foreign cost of capital, currency risk premium and effects of capital flows on the exchange rate. This shock is very persistent and has its main effect after a lag of about 2 years. The other two foreign shocks, world demand shocks and commodity export price shocks were also found to be important, the former having a strong but transitory short term effect and the latter a medium term effect in New Zealand.

The most important domestic shock in both countries was the investment specific shock. In the model, this shock affects the efficiency with which investment is transformed into productive capital. This shock played an important role in the improvement in both countries'current account positions in the late 1990s. The importance of this shock suggests that a richer specification of the financial sector may help in understanding the investment specific factors at work.

Monetary and fiscal policy shocks were found to have relatively small effects. However, these shocks represent deviations from estimated policy rules, leaving open the possibility that the parameterisations of the policy reaction functions may be relevant. In Chile, tighter monetary policy leads to an improvement in the current account as aggregate demand contracts, leading to lower imports (despite price effects) and lower exports (because of price effects). In New Zealand, the effect of a monetary policy shock on the current account is more ambiguous. The same positive effect works through aggregate demand, but the rise in the domestic interest rate increases debt service payments on the large stock of external liabilities, worsening the investment income account. The net effect on the current account is small, fluctuating around zero.

While the models were very similar and there are anumber of similarities between the two countries, some structural differences led to interesting differences in the responses to some shocks such as an exogenous exchange rate depreciation which is expansionary in New Zealand but contractionary in Chile.

Counterfactual experiments explored the effects of original $\sin$ in Chile and the aggressiveness of the monetary response in New Zealand. If Chile's external debt was denominated in Chilean pesos, GDP and aggregate demand components would be more resilient to external shocks (commodity price, foreign demand, and interest rate). Monetary policy innovations would also have less effect on the current account. Moreover, the required movement in the real exchange rate to generate an adjustment in the current account would tend to be smaller. Our counterfactual experiment for New Zealand revealed that, in the framework of our model, a more or less aggressive monetary policy can do little to offset the effects of shocks to foreign financial conditions, which account for the vast bulk of exchange rate variance. For the other three shocks that are important for the current account, a less aggressive monetary policy response reduces exchange swings, while having little effect on the current account. However, the scope for more smoothing is limited by the already-high estimated coefficient in the policy rule.

Overall out results suggest that the current accounts of New Zealand and Chile are playing a useful role as shock absorbers, particularly with respect to foreign shocks and investmentspecific shocks. In our models, households are able to smooth consumption over time in the face of shocks, by borrowing from and lending to nonresidents. 


\section{References}

Adolfson, M., S. Laséen, J. Lindé and M. Villani (2005), "Bayesian Estimation of an Open Economy DSGE Model with Incomplete Pass-Through", Working Paper No. 179, Sveriges Riksbank.

Aguiar, M. and G. Gopinath (2007), "The Role of Interest Rates and Productivity Shocks in Emerging Market Fluctuations", presented at the Tenth Annual Conference of the Central Bank of Chile, 9 November 2006. http://www.bcentral.cl/eng/conferences- seminars/annualconferences/2006/09112006.htm

Agosin, M. (1998), “Business and Household Saving in Chile.” Working paper 158. University of Chile, Economics Department.

Altig, D., Christiano, L., Eichenbaum, M. and J. Lindé (2004), "Firm-Specific Capital, Nominal Rigidities and the Business Cycle", Working Paper No. 176, Sveriges Riksbank.

Bennett, H., N. Loayza, K. Schmidt-Hebbel (2001) "Un estudio del ahorro agregado por agentes económicos en Chile" in F. Morandé and R. Vergara (eds.) Análisis empírico del ahorro en Chile, Santiago, Chile. Central Bank of Chile.

Brubakk, L. T. A. Husebø, S. McCaw, D. Muir, B. Naug, K. Olsen, Ø. Røisland, T. Sveen and B.R. Wilhelmsen (2005), "Finding NEMO: From the Global Economy Model (GEM) to a national core model,",manuscript, Norges Bank.

Buckle, B, and A. Drew (2006), "Testing stabilisation policy limits in a small open economy", Editors' summary of the New Zealand Treasury and Reserve Bank of New Zealand Macroeconomic Policy Forum, June 2006. http://www.rbnz.govt.nz/research/workshops/12jun06/2837468.html

Buiter, W. (2006), "Stabilisation Policy in New Zealand: Counting your blessings, one by one", paper presented at the New Zealand Treasury and Reserve Bank of New Zealand Macroeconomic Policy Forum "Testing stabilisation policy limits in a small open economy", June 2006. Discussion by Pierre Siklos. http://www.rbnz.govt.nz/research/workshops/12jun06/2837468.html

Calvo, G. (1983), "Staggered prices in utility-maximizing framework," Journal of Monetary Economics, 12, 383-98.

Calvo, G., L. Leiderman, and C. Reinhart (1996) "Inflows of capital to developing countries in the 1990s", Journal of Economic Perspectives 10(2) pp. 123-139.

Caputo, R., F. Liendo and J. P. Medina (2006), "New Keynesian models for the Inflation Targeting period in Chile," Forthcoming in F. Mishkin and K. Schmidt-Hebbel (eds.) Monetary Policy under Inflation Targeting. Santiago, Central Bank of Chile

Caputo, R., J. P. Medina and C. Soto (2006), "Nominal Rigidities, Indexation and Inflation Persistency in Chile: A Structural Investigation” Mimeo, Central Bank of Chile.

Céspedes, L. F., M. Ochoa and C. Soto (2005), “An Estimated New Keynesian Phillips Curve for Chile," Working Paper 355, Central Bank of Chile.

Christiano, L., Eichenbaum, M. and C. Evans (2005), "Nominal Rigidities and the Dynamic Effects of a Shock to Monetary Policy," Journal of Political Economy 113, 1-45. 
Cox, P., E. Parrado and J. Ruiz-Tagle (2007), "The distribution of assets, debt and income among Chilean households", Proceedings of the Irving Fischer Committee Conference on "Measuring the financial position of the household sector", Basel, 30-31 August 2006, IFC Bulletin No 26 Vol 2.

De Gregorio, J. (2006) "Bonanza del Cobre: Impacto Macroeconómico y Desafíos de Política" Presented at the seminar "Administrando el auge del Cobre" organized by Libertad y Desarrollo and Expansiva. Santiago, Chile. May.

DeJong, D., B. Ingram and C. Whiteman (2000). A Bayesian approach to dynamic macroeconomics. Journal of Econometrics 98, 201-223.

Edwards, S. (2006), "External Imbalances in New Zealand", paper presented at the New Zealand Treasury and Reserve Bank of New Zealand Macroeconomic Policy Forum "Testing stabilisation policy limits in a small open economy", June 2006. Discussion by William Cline. http://www.rbnz.govt.nz/research/workshops/12jun06/2837468.html

Eichengreen, B., R. Hausmann, and U. Panizza (2005), “The Pain of Original Sin.” University of California, Berkeley, Economics Department. In Other People's Money: Debt Denomination and Financial Instability in Emerging Market Economies, edited by B. Eichengreen y R. Hausmann, 13-47. University of Chicago Press.

Erceg, C., D W. Henderson and A. T. Levin (2000) "Optimal monetary policy with staggered wage and price contracts" Journal of Monetary Economics, 46 pp. 281-313

Feldstein, M and C. Horioka (1980) "Domestic Savings and International Capital Flows" NBER Working Paper, 310

Fernández-Arias, E., and P. J. Montiel (1996) "The Surge in Capital Inflows to Developing Countries: An Analytical Overview" World Bank Economic Review 10: 51-77

Fernandez-Villaverde, J. and J. Rubio-Ramirez (2007), "Estimating macroeconomic models: a likelihood approach", Review of Economic Studies, 74 (4)

Fuentes, R., A. Jara, K. Schmidt-Hebbel, and others. 2003. "Efectos de la nominalización de la política monetaria en Chile.” Working paper 197. Santiago: Central Bank of Chile.

Greenwood, J., Z. Hercowitz, and P. Krusell, (2000) "The Role of Investment-Specific Technological Change in theBusiness Cycle", European Economic Review 44 (1), 91-115.

Grenville, S (2006), "Macroeconomic Policy Challenges: Monetary Policy", paper presented at the New Zealand Treasury and Reserve Bank of New Zealand Macroeconomic Policy Forum "Testing stabilisation policy limits in a small open economy", June 2006. Discussion by Christopher Allsopp. http://www.rbnz.govt.nz/research/workshops/12jun06/2837468.html

Hodgetts, B, P. Brigs and M. Smith (2006), "Trends in Saving and Wealth", paper presented at Reserve Bank of New Zealand workshop entitled Housing, Savings, and the Household Balance Sheet, Wellington, 14 November 2006.

Jacquinot, P, R. Mestre and M. Spitzer (2006), "An Open-Economy DSGE Model of the Euro Area" (July 2006), ECB Working Paper Series

Lane, P. and G. Milesi Ferretti (2001), "The External Wealth of Nations: Measures of Foreign Assets and Liabilities for Industrial and Developing Countries," Journal of International Economics, Vol. 55, pp. 263-940. 
Liu, P. (2006), "A Small New Keynesian Model of the New Zealand Economy" Reserve Bank of New Zealand Discussion Paper DP2006/03.

Lubik and Shorfheide (2005) "A Bayesian Look at New Open Economy Macroeconomics" NBER Macroeconomics Annual.

Lucas, R. (1976), “Econometric Policy Evaluation: A Critique,'In K. Brunner and A. H. Meltzer (eds.), The Phillips Curve and Labor Markest. Amsterdam: North-Holland, 19-46.

Marcel, M, M. Tokman, R. Valdés, P. Benavides (2001), "Structural budget balance: the pilar of the new Chilean fiscal policy rule", Journal Economía Chilena (The Chilean Economy), 4 (3) p $15-27$

Massad, C. (2003) Políticas del Banco Central de Chile 1997-2003 Central Banf of Chile: Santiago, Chile

Medina, J. P. and C. Soto (2006a), "Model for Analysis and Simulations, A New DSGE for the Chilean Economy" Mimeo, Central Bank of Chile.

Medina, J. P. and C. Soto (2006b), "Copper Price, Fiscal Policy and Business Cycle in Chile," Mimeo, Central Bank of Chile.

Morandé, F. (1998), “Saving in Chile. What Went Right?” Journal of Development Economics 57: 201-228.

Morandé, F. (2002), "Nominalización de la tasa de política monetaria: Debate y consecuencias." Cuadernos de Economía 39(117): 239-52.

Munro, A. and R. Sethi (2006), "The Present Value Model and New Zealand's Current Account", Discussion Paper 2006/12. Wellington Reserve Bank of New Zealand.

Munro, A. and R. Sethi (2007), "“Understanding the New Zealand Current Account: A Structural Approach." Discussion paper DP2007/10. Wellington: Reserve Bank of New Zealand.

Parrado, E. (2001)“Shocks externos y transmision de la Política Monetaria en Chile,” Economía Chilena 4(3): 29-52

Schmitt-Grohé, S. and M. Uribe (2003), “Closing Small Open Economy Models," Journal of International Economics, 61, 163-185.

Schmidt-Hebbel, K (2006), "New Zealand's Macroeconomic Framework in International Comparison", paper presented at the New Zealand Treasury and Reserve Bank of New Zealand Macroeconomic Policy Forum "Testing stabilisation policy limits in a small open economy", June 2006. Discussion by John Edwards. http://www.rbnz.govt.nz/research/workshops/12jun06/2837468.html

Schmidt Hebbel, K and M. Tapia, (2002) "Monetary Policy Implementation and Results in Twenty Inflation-Targeting Countries," Working Papers Central Bank of Chile 166, Central Bank of Chile

Smets, F. and R. Wouters (2003a), "An Estimated Stochastic Dynamic General Equlibrium Model of the Euro Area," Journal of the European Ecoomic Association, 1, 1123-75.

Smets, F. and R. Wouters (2003b), "Shocks and Frictions in US Business Cycles: A Bayesian DSGE Approach,” Manuscript, European Central Bank. 
West, K. (2003), "Monetary policy and the volatility of real exchange rates in New Zealand" Reserve Bank of New Zealand Discussion Paper DP2003/09. 
Table 1

\section{Calibrated parameters}

Parameter Chile New Zealand Definition

\begin{tabular}{lccl}
$g_{y}$ (annual basis) & $3.0 \%$ & $1.5 \%$ & per capita productivity growth \\
$\pi$ (annual basis) & $3.0 \%$ & $2.0 \%$ & inflation rate \\
$r$ (annual basis) & $4.1 \%$ & $3.0 \%$ & real interest rate \\
$\delta$ (annual basis) & $6.8 \%$ & $8.0 \%$ & depreciation rate of capital \\
$\chi$ & 0.40 & 0.90 & domestic ownership of commodity production \\
$\frac{X-M}{Y}$ & $2 \%$ & $1.3 \%$ & net export-GDP ratio \\
$\frac{C A}{Y}$ & $-1.8 \%$ & $-5.0 \%$ & current account - GDP ratio \\
$B$ & -0.30 & -0.70 & -(debt-GDP ratio) \\
$\frac{G}{Y}$ & $12 \%$ & $17 \%$ & government expenditure - GDP ratio \\
$\frac{Y_{S}}{Y}$ & $10 \%$ & $14 \%$ & commodity production - GDP ratio \\
$\frac{I}{Y}$ & $26.6 \%$ & $22.8 \%$ & Investment-GDP ratio \\
$\frac{C}{Y}$ & $59.3 \%$ & $58.8 \%$ & Consumption-GDP ratio \\
$\gamma_{C}$ & $70 \%$ & $70 \%$ & home goods share in consumption \\
$\gamma_{I}$ & $40 \%$ & $25 \%$ & home goods share in investment \\
$\rho_{p_{S}^{*}}$ & 0.50 & 0.00 & fraction of non-Ricardian households \\
$\sigma_{p_{S}^{*}}$ & 0.98 & 0.99 & auto-regressive coefficient of commodity price \\
$\rho_{v}$ & 8.85 & 3.51 & standard deviation of commodity price innovation \\
$\eta_{H}$ & 0.00 & 0.00 & auto-regressive coefficient of monetary policy shocks \\
$\lambda$ & 0.68 & labor share in the home goods production \\
\hline & & &
\end{tabular}


Table 2

Prior Distributions

\begin{tabular}{|c|c|c|c|c|c|}
\hline Parameter & Country & mean/mode & s.d./d.f. & Shape & $90 \%$ Interval \\
\hline$\sigma_{L}$ & Both & 1.000 & 1.000 & Gamma & $0.051-2.996$ \\
\hline$h$ & Both & 0.500 & 0.250 & Beta & $0.097-0.903$ \\
\hline$\phi_{L}$ & Both & 0.750 & 0.100 & Beta & $0.570-0.897$ \\
\hline$\chi_{L}$ & Both & 0.500 & 0.250 & Beta & $0.097-0.903$ \\
\hline$\eta_{C}$ & Both & 1.000 & 5.000 & Inv. Gamma & $0.655-3.045$ \\
\hline$\eta_{I}$ & Both & 1.000 & 5.000 & Inv. Gamma & $0.655-3.045$ \\
\hline$\mu_{S}$ & Both & 2.000 & 3.000 & Inv. Gamma & $1.271-9.784$ \\
\hline$\phi_{H_{D}}$ & Both & 0.750 & 0.100 & Beta & $0.570-0.897$ \\
\hline$\chi_{H_{D}}$ & Both & 0.500 & 0.250 & Beta & $0.097-0.903$ \\
\hline$\phi_{H_{F}}$ & Both & 0.750 & 0.100 & Beta & $0.570-0.897$ \\
\hline$\chi_{H_{F}}$ & Both & 0.500 & 0.250 & Beta & $0.097-0.903$ \\
\hline$\phi_{F}$ & Both & 0.750 & 0.100 & Beta & $0.570-0.897$ \\
\hline$\chi_{F}$ & Both & 0.500 & 0.250 & Beta & $0.097-0.903$ \\
\hline$\psi_{i}$ & Chile & 0.700 & 0.100 & Beta & $0.524-0.853$ \\
\hline$\psi_{\pi}$ & Chile & 1.500 & 0.150 & Gamma & $1.262-1.755$ \\
\hline$\psi_{y}$ & Chile & 0.500 & 0.150 & Gamma & $0.281-0.770$ \\
\hline$\psi_{\text {rer }}$ & Chile & 0.200 & 0.100 & Gamma & $0.068-0.388$ \\
\hline$\psi_{i}$ & New Zealand & 0.750 & 0.100 & Beta & $0.570-0.897$ \\
\hline$\psi_{\pi}$ & New Zealand & 1.500 & 0.100 & Gamma & $1.339-1.668$ \\
\hline$\psi_{y}$ & New Zealand & 0.500 & 0.100 & Gamma & $0.348-0.675$ \\
\hline$\eta^{*}$ & Both & 1.000 & 4.000 & Inv. Gamma & $0.645-3.659$ \\
\hline$\varrho_{f}$ & Chile & 0.010 & 4.000 & Inv. Gamma & $0.006-0.037$ \\
\hline$\varrho_{d}$ & New Zealand & 0.001 & 4.000 & Inv. Gamma & $0.001-0.004$ \\
\hline$\rho_{a_{H}}$ & Both & 0.700 & 0.200 & Beta & $0.321-0.965$ \\
\hline$\rho_{y_{S}}$ & Both & 0.700 & 0.200 & Beta & $0.321-0.965$ \\
\hline$\rho_{Y^{*}}$ & Both & 0.700 & 0.200 & Beta & $0.321-0.965$ \\
\hline$\rho_{\zeta_{C}}$ & Both & 0.700 & 0.200 & Beta & $0.321-0.965$ \\
\hline$\rho_{\zeta_{I}}$ & Both & 0.700 & 0.200 & Beta & $0.321-0.965$ \\
\hline$\rho_{G}$ & Both & 0.300 & 0.050 & Beta & $0.221-0.385$ \\
\hline$\rho_{i^{*}}$ & Both & 0.950 & 0.050 & Beta & $0.849-0.998$ \\
\hline$\rho_{T}$ & Both & 0.700 & 0.200 & Beta & $0.321-0.965$ \\
\hline$\sigma_{a_{H}}$ & Both & 1.000 & 3.000 & Inv. Gamma & $0.635-4.892$ \\
\hline$\sigma_{y_{S}}$ & Both & 1.000 & 3.000 & Inv. Gamma & $0.635-4.892$ \\
\hline$\sigma_{Y^{*}}$ & Both & 1.000 & 3.000 & Inv. Gamma & $0.635-4.892$ \\
\hline$\sigma_{i^{*}}$ & Chile & 0.250 & 3.000 & Inv. Gamma & $0.159-1.223$ \\
\hline$\sigma_{i^{*}}$ & New Zealand & 0.500 & 3.000 & Inv. Gamma & $0.318-2.446$ \\
\hline$\sigma_{m}$ & Both & 0.200 & 3.000 & Inv. Gamma & $0.127-0.978$ \\
\hline$\sigma_{\zeta_{C}}$ & Both & 1.000 & 3.000 & Inv. Gamma & $0.635-4.892$ \\
\hline$\sigma_{G}$ & Both & 1.000 & 3.000 & Inv. Gamma & $0.635-4.892$ \\
\hline$\sigma_{\zeta_{I}}$ & Both & 1.000 & 3.000 & Inv. Gamma & $0.635-4.892$ \\
\hline$\sigma_{T}$ & Both & 0.200 & 3.000 & Inv. Gamma & $0.127-0.978$ \\
\hline
\end{tabular}

For inverse gamma distributions, degrees of freedom are presented 
Table 3

Posterior Distributions (mode)

\begin{tabular}{|c|c|c|c|}
\hline Parameter & & Chile & New Zealand \\
\hline$\sigma_{L}$ & Inverse elasticity of labour supply & 0.164 & 0.001 \\
\hline$h$ & Consumption habit parameter & 0.572 & 0.813 \\
\hline$\phi_{L}$ & Calvo parameter: wages & 0.806 & 0.911 \\
\hline$\chi_{L}$ & Indexation parameter: wages & 0.058 & 0.102 \\
\hline$\eta_{C}$ & Consumption elast. of subst: home-foreign goods & 1.221 & 1.239 \\
\hline$\eta_{I}$ & Investment elast. of subst: home-foreign goods & 1.107 & 1.031 \\
\hline$\mu_{S}$ & Investment adj. cost parameter & 2.288 & 1.694 \\
\hline$\phi_{H_{D}}$ & Calvo parameter: home goods sold domestically & 0.486 & 0.631 \\
\hline$\chi_{H_{D}}$ & Indexation: home goods sold domestically & 0.127 & 0.086 \\
\hline$\phi_{H_{F}}$ & Calvo parameter: home goods sold abroad & 0.966 & 0.915 \\
\hline$\chi_{H_{F}}$ & Indexation: home goods sold abroad & 0.227 & 0.181 \\
\hline$\phi_{F}$ & Calvo parameter: imports & 0.838 & 0.968 \\
\hline$\chi_{F}$ & Indexation: imports & 0.806 & 0.178 \\
\hline$\psi_{i, 1}, \psi_{i}$ & Monetary Policy: interest rate smoothing & 0.670 & 0.897 \\
\hline$\psi_{\pi, 1}, \psi_{\pi}$ & Monetary policy: inflation response & 1.244 & 1.455 \\
\hline$\psi_{y, 1}, \psi_{y}$ & Monetary policy: output response & 0.184 & 0.389 \\
\hline$\psi_{r e r, 1}$ & Monetary policy: exchange rate response & 0.052 & - \\
\hline$\psi_{i, 2}$ & Monetary Policy: interest rate smoothing & 0.778 & - \\
\hline$\psi_{\pi, 2}$ & Monetary policy: inflation response & 1.632 & - \\
\hline$\psi_{y, 2}$ & Monetary policy: output response & 0.305 & - \\
\hline$\eta^{*}$ & Foreign price elast. of demand & 0.999 & 2.007 \\
\hline$\varrho$ & Risk premium parameter & 0.016 & 0.001 \\
\hline$\rho_{a_{H}}$ & AR(1) coeff. Transitory productivity shock & 0.901 & 0.69 \\
\hline$\rho_{y_{S}}$ & AR(1) coeff. Commodity production shock & 0.642 & 0.907 \\
\hline$\rho_{Y^{*}}$ & AR(1) coeff. Foreign demand shock & 0.736 & 0.653 \\
\hline$\rho_{\zeta_{C}}$ & AR(1) coeff. Consumption preference shock & 0.227 & 0.332 \\
\hline$\rho_{\zeta_{I}}$ & AR(1) coeff. Investment specific shock & 0.862 & 0.412 \\
\hline$\rho_{\zeta_{G}}$ & AR(1) coeff. Fiscal shock & 0.315 & - \\
\hline$\rho_{G}$ & AR(1) coeff. Fiscal shock & - & 0.393 \\
\hline$\rho_{i^{*}}$ & AR(1) coeff. Foreign financial conditions & 0.985 & 0.923 \\
\hline$\rho_{T}$ & AR(1) coeff. Permanent productivity shock & 0.987 & 0.156 \\
\hline$\sigma_{a_{H}}$ & StDev of transitory productivity shock & 1.498 & 1.915 \\
\hline$\sigma_{y_{S}}$ & StDev of commodity production shock & 28.418 & 1.993 \\
\hline$\sigma_{Y^{*}}$ & StDev of foreign demand shock & 10.275 & 8.847 \\
\hline$\sigma_{i^{*}}$ & StDev of foreign financial conditions shock & 0.332 & 0.36 \\
\hline$\sigma_{m}$ & StDev of monetary policy shock & 0.392 & 0.189 \\
\hline$\sigma_{\zeta_{C}}$ & StDev of consumption preference shock & 5.032 & 6.291 \\
\hline$\sigma_{\zeta_{G}}$ & StDev of fiscal shock & 12.18 & - \\
\hline$\sigma_{g}$ & StDev of fiscal shock & - & 9.739 \\
\hline$\sigma_{\zeta_{I}}$ & StDev of investment-specific shock & 7.125 & 10.291 \\
\hline$\sigma_{T}$ & StDev of premanent technology shock & 0.19 & 0.498 \\
\hline
\end{tabular}




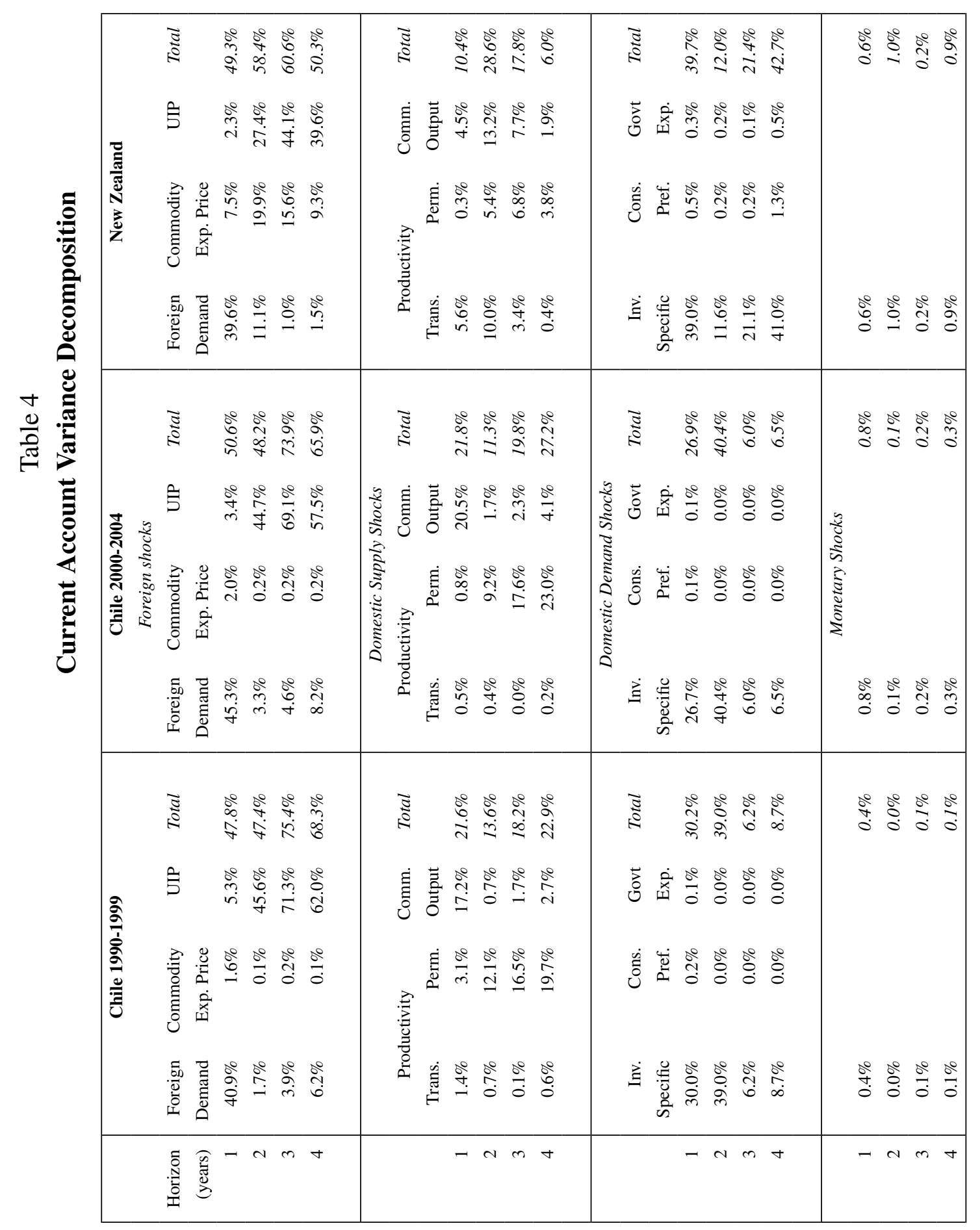


Figure 1

Chile and New Zealand: Current Account and Related Variables
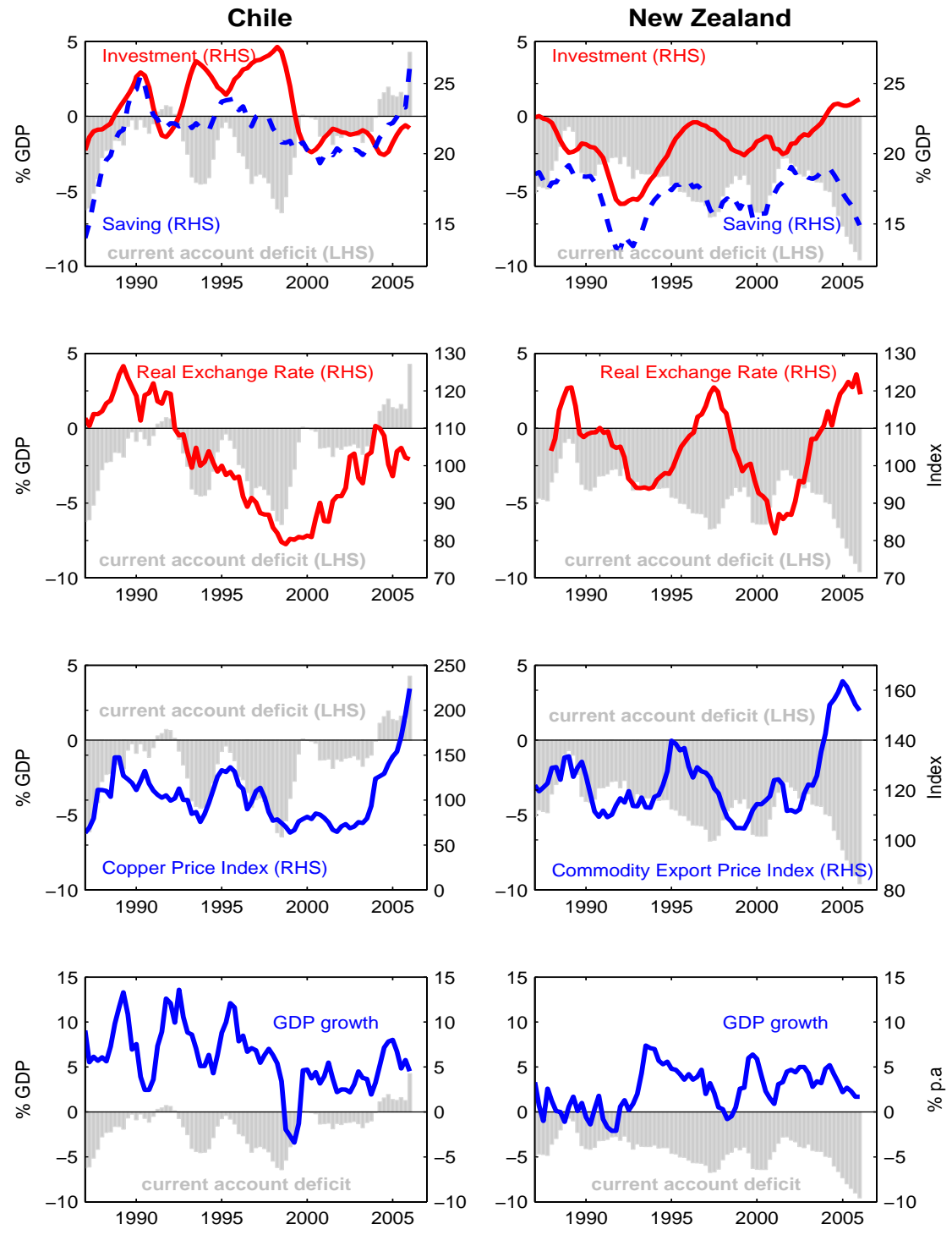
Figure 2

Chile: Impulse Responses
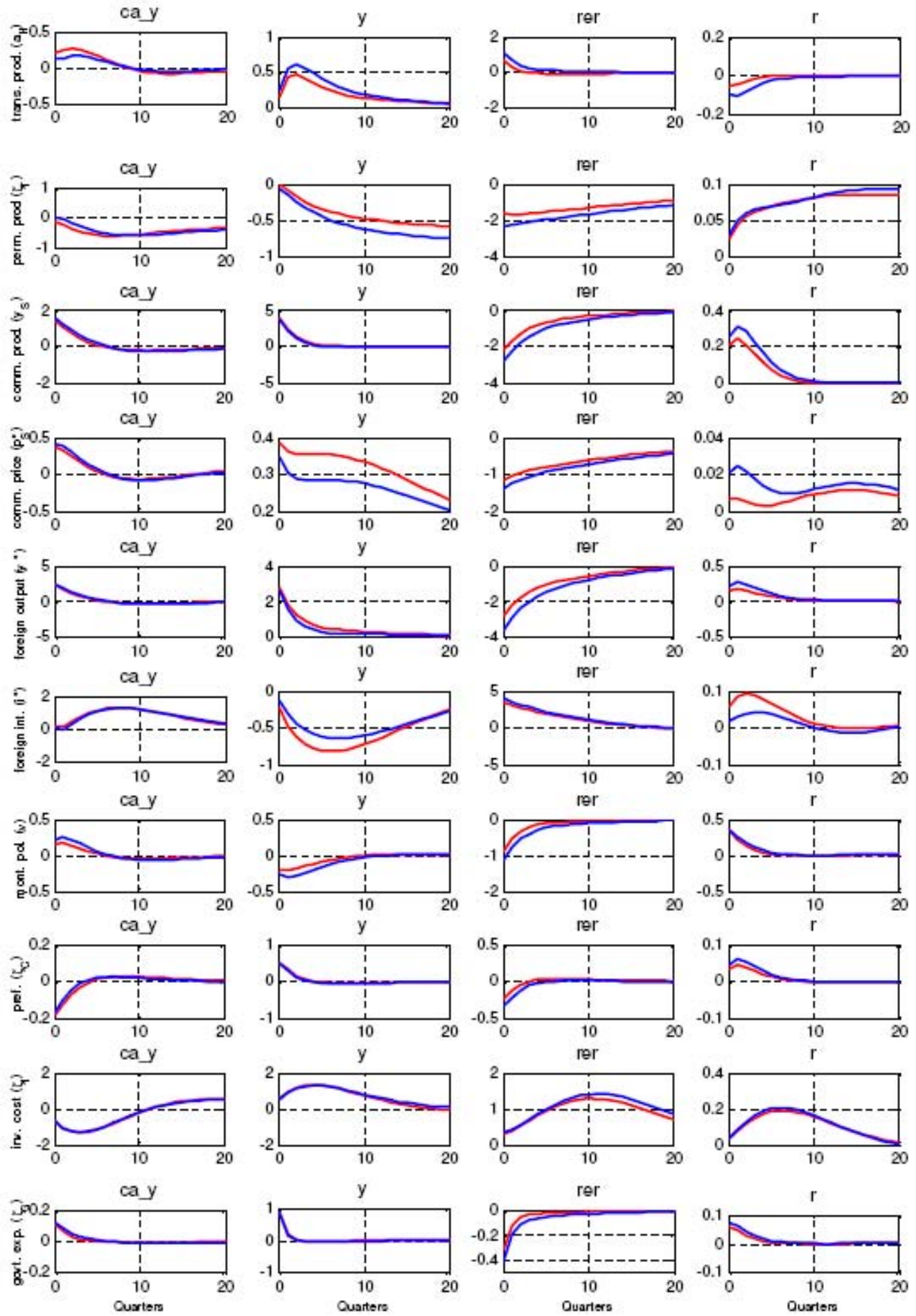
Figure 3

Chile: Impulse Responses (cont...)
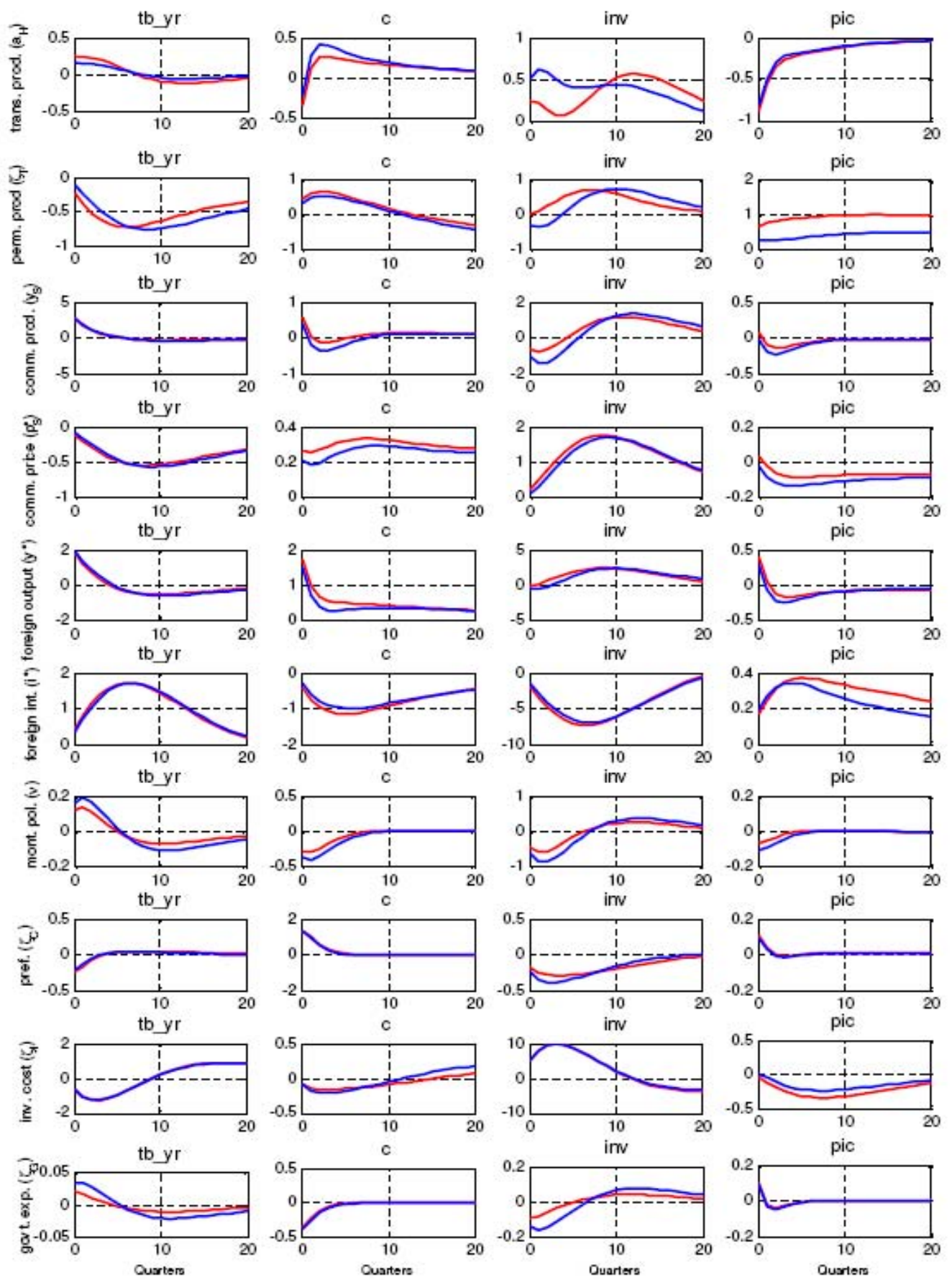
Figure 4

New Zealand: Impulse Responses
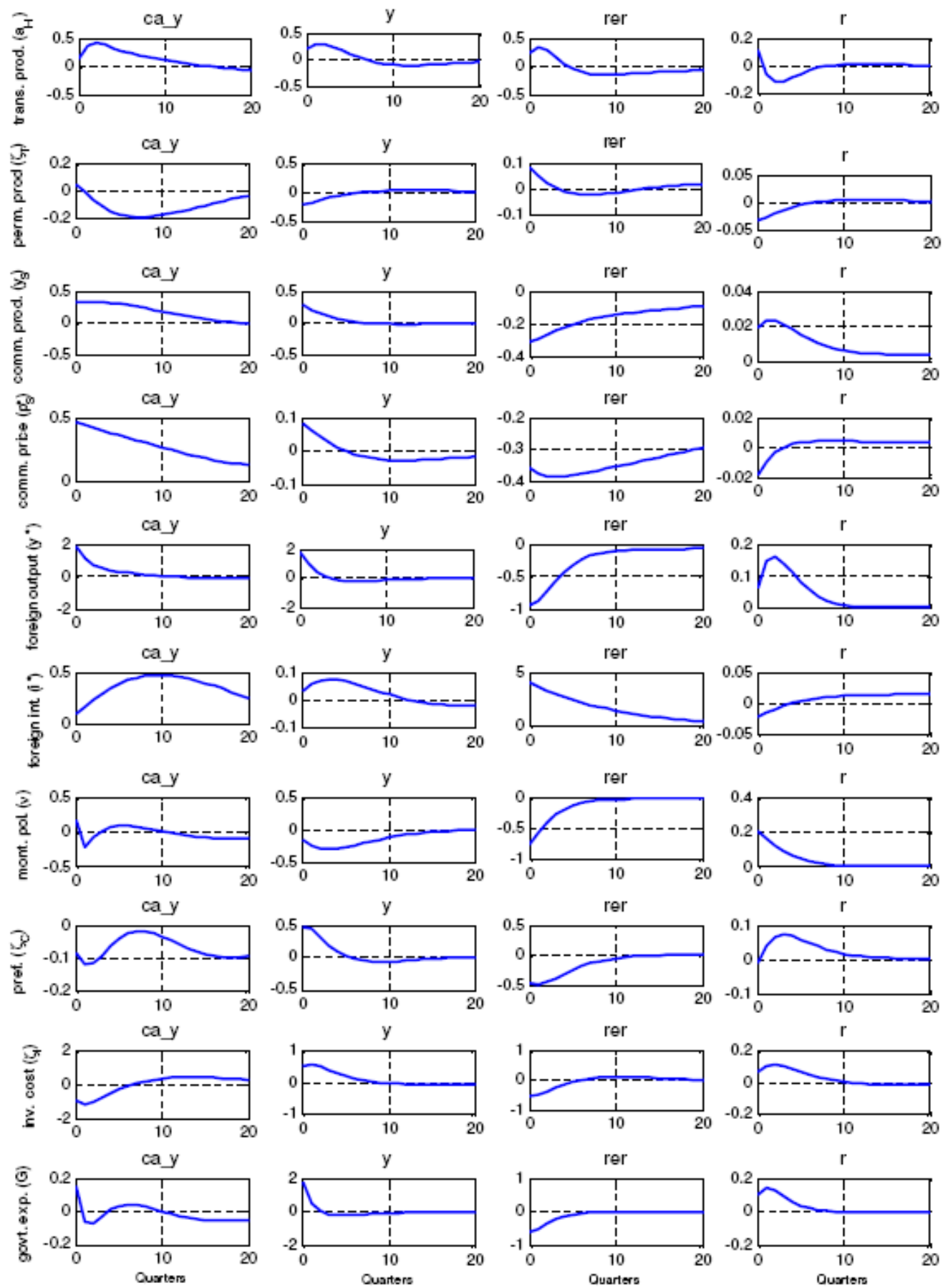
Figure 5

New Zealand: Impulse Responses (cont...)
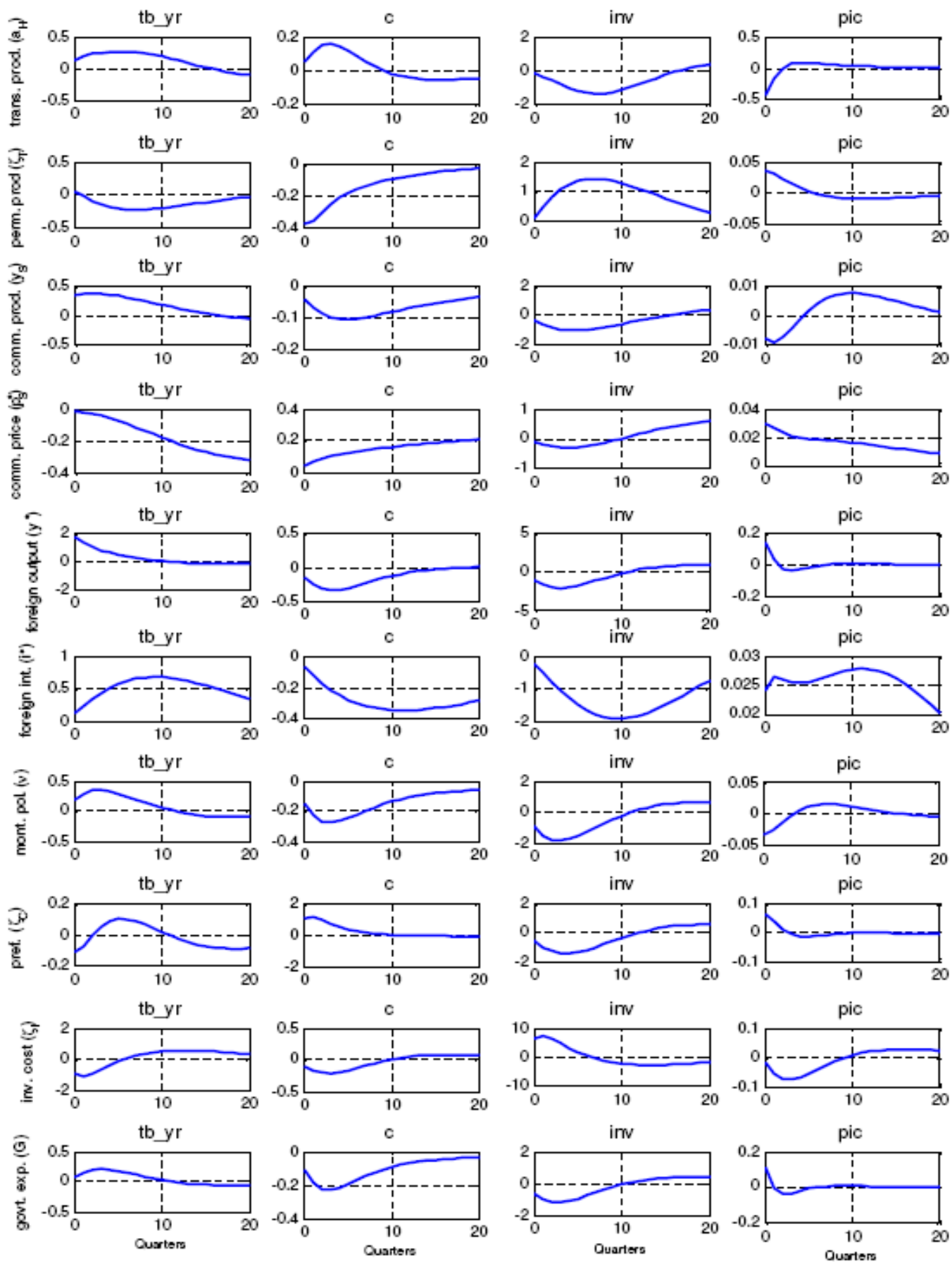
Figure 6

\section{Chile: Latent Variables}
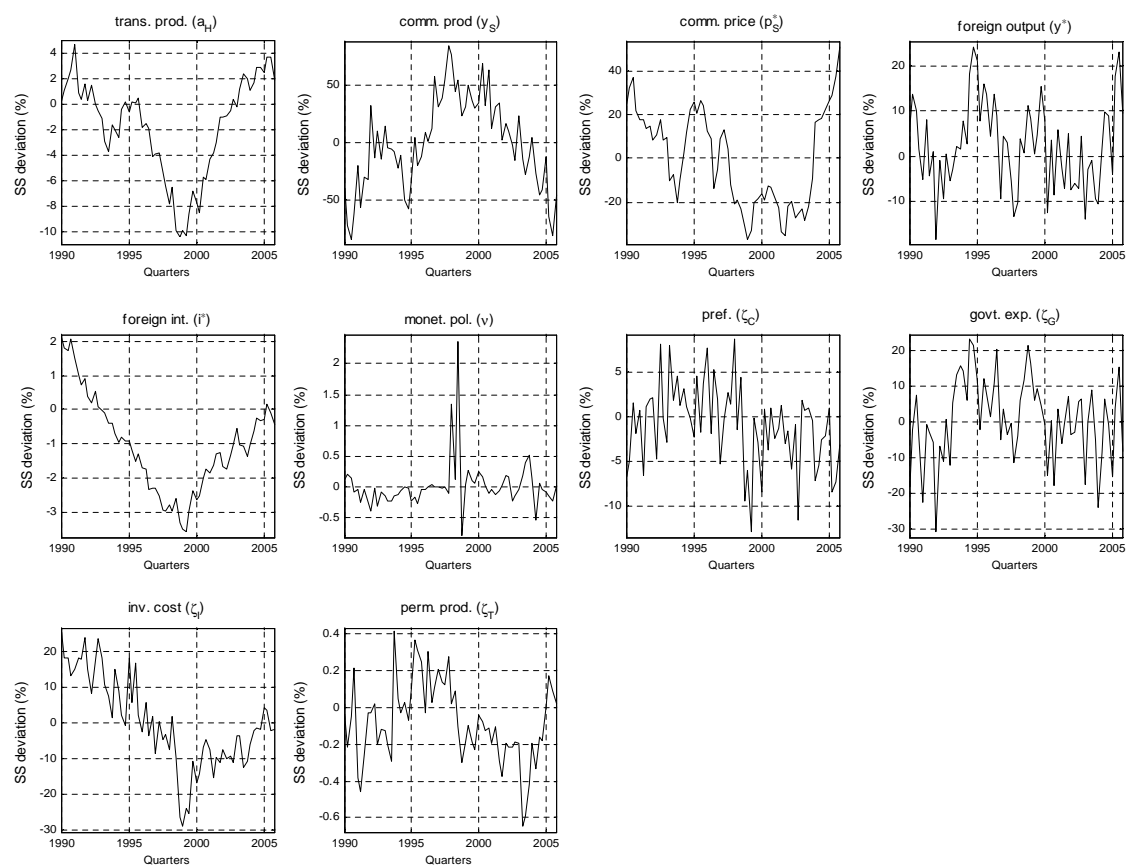
Figure 7

New Zealand: Latent Variables
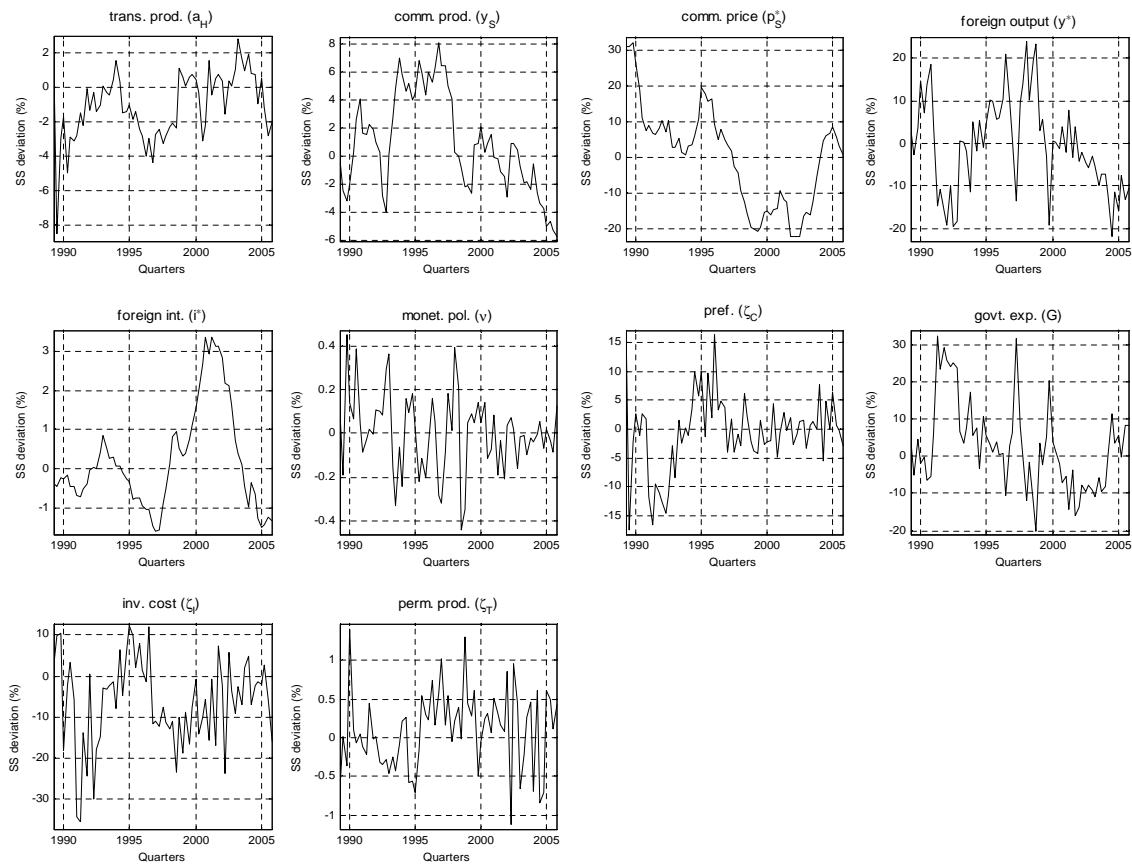
Figure 8

Chile: Historical Decomposition of the Current Account, 1990-2005
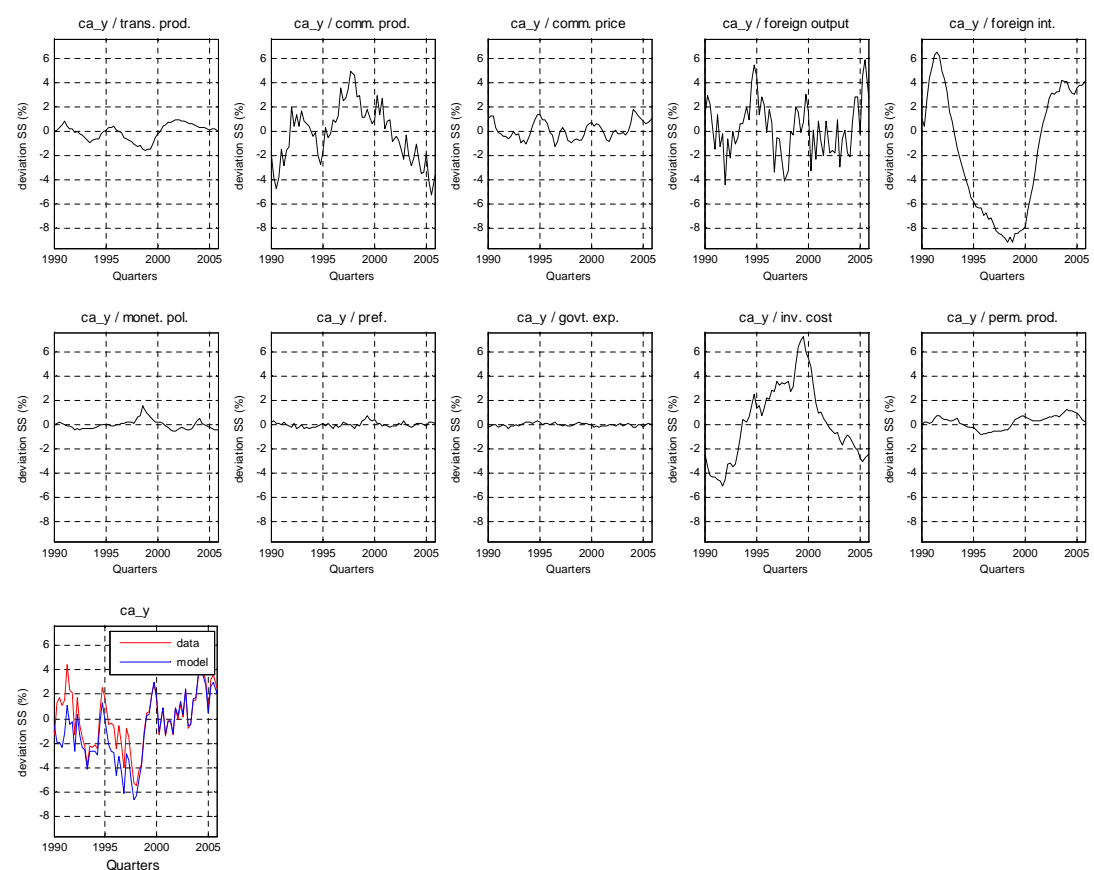
Figure 9

New Zealand: Historical Decomposition of the Current Account, 1990-2005
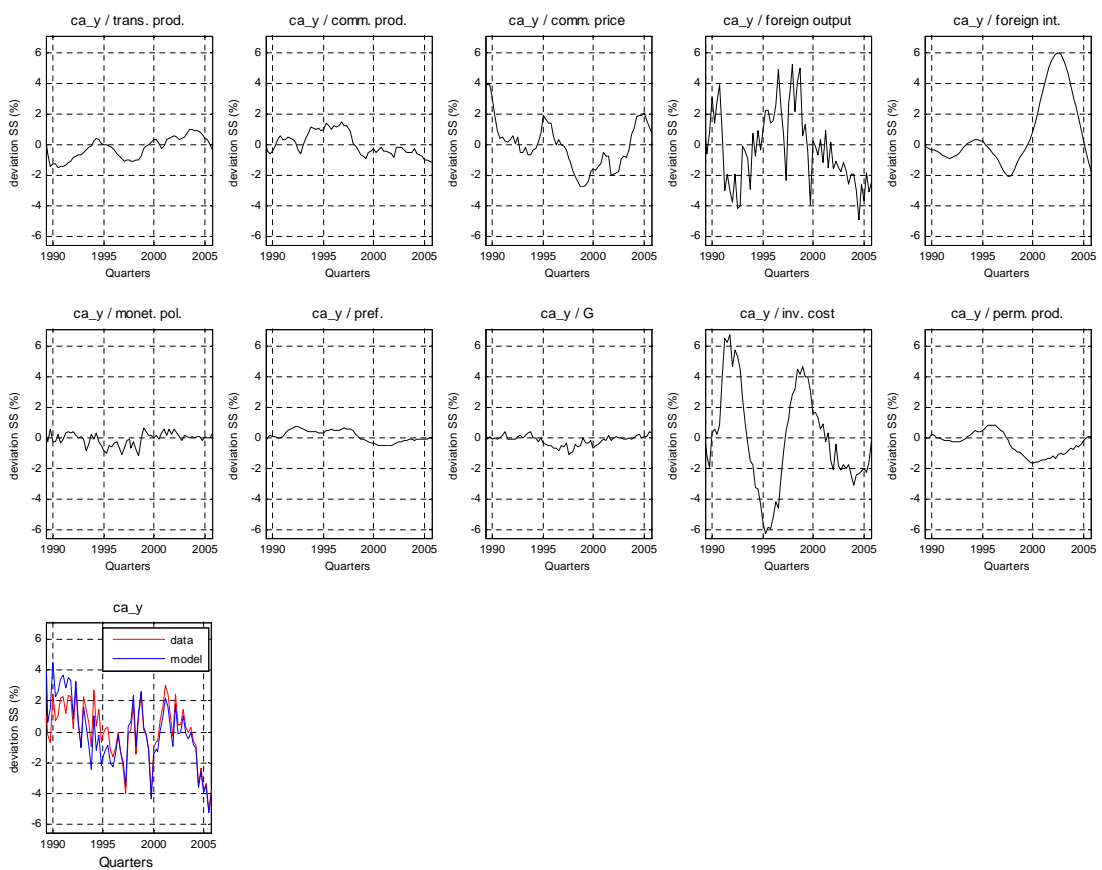
Figure 10

Impulse Responses: Domestic vs Foreign Currency Denominated Debt in Chile

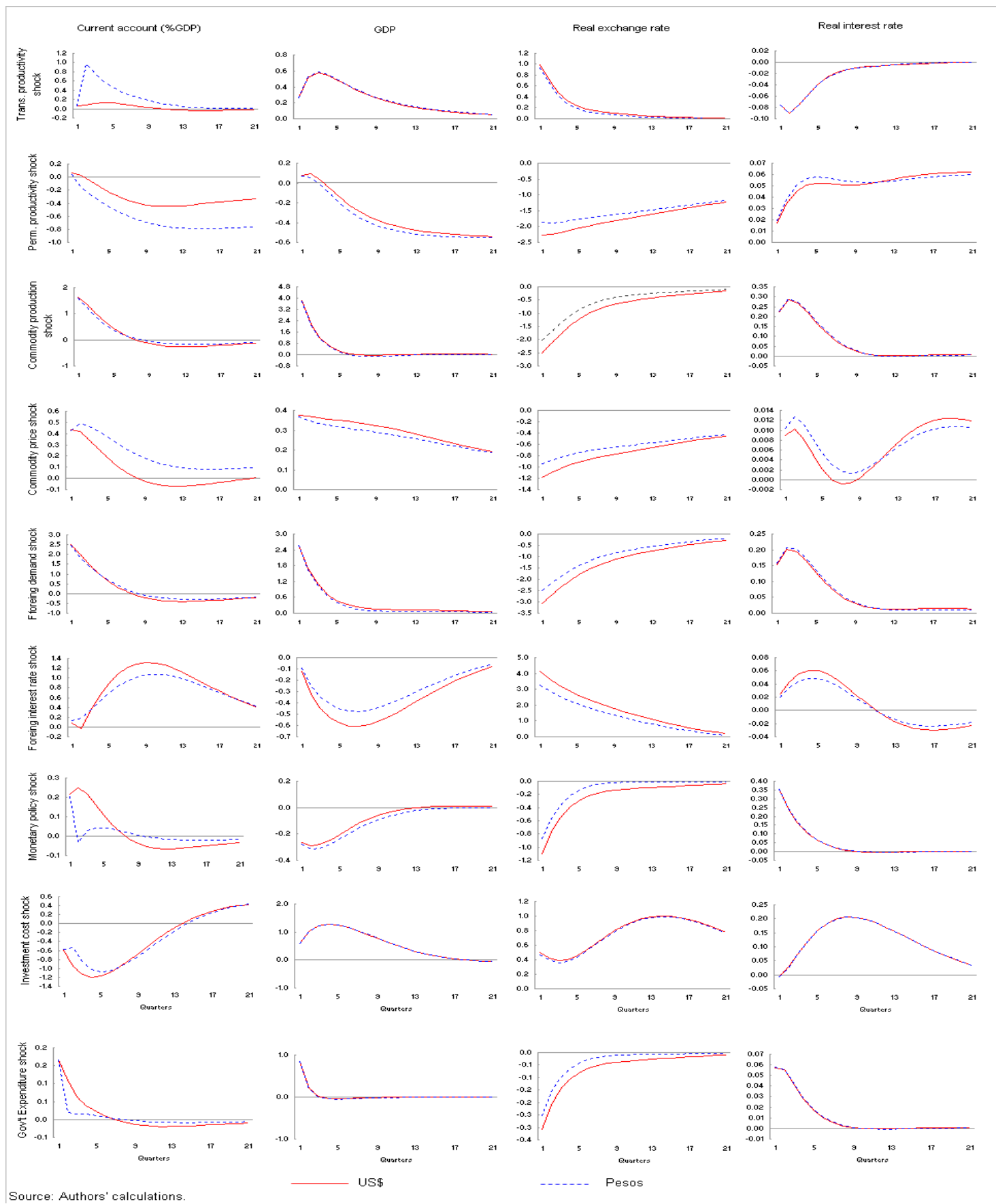


Figure 11

Impulse Responses: More/Less Aggressive Monetary Policy in New Zealand

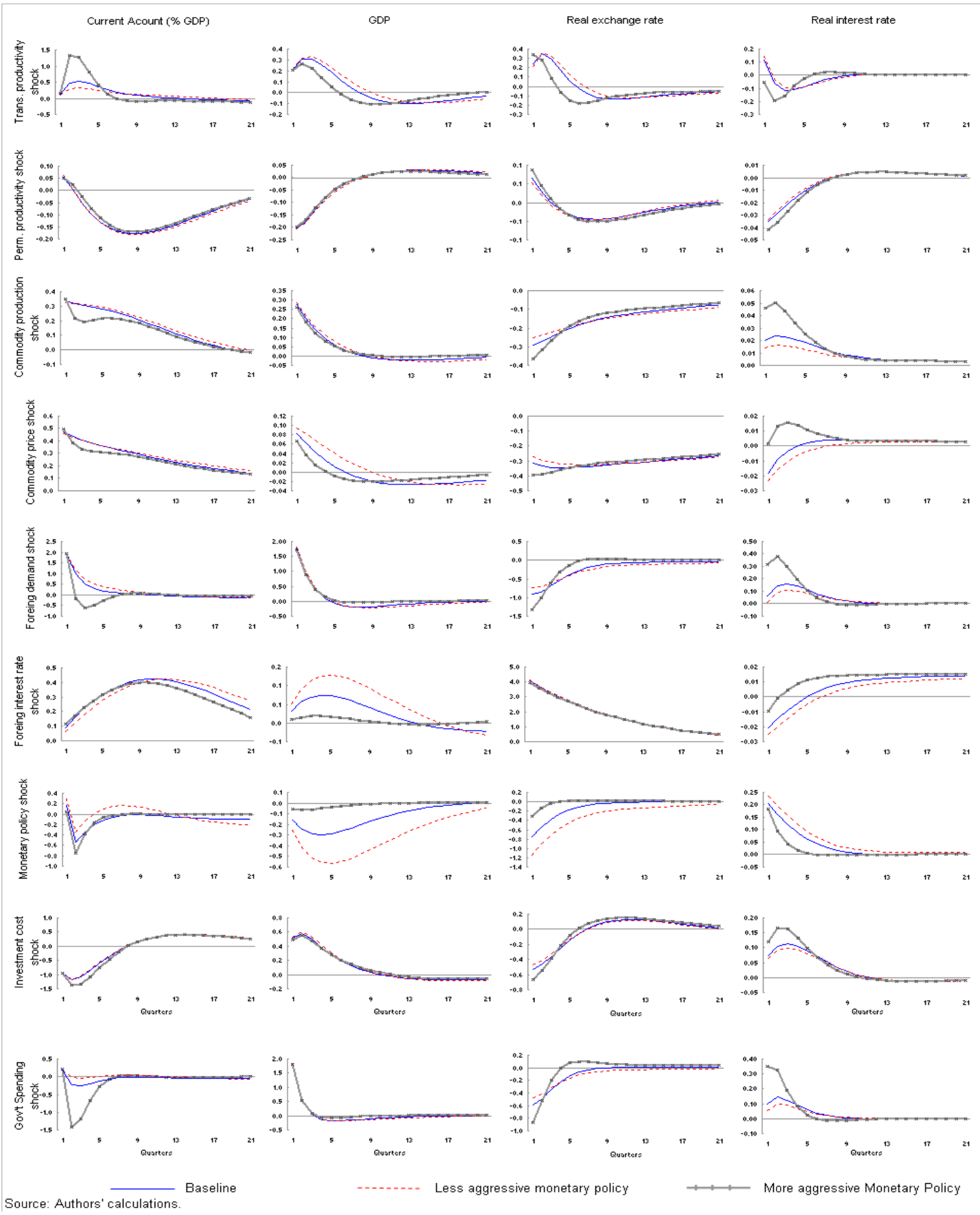

